\title{
Geografía de la renta de los hogares en España a nivel municipal: nuevos datos y nuevas posibilidades de geovisualización, exploración y análisis espacial en entornos cloud
}

\author{
Geography of household income in Spain at municipal level: \\ new data and new possibilities for geovisualization, exploration, \\ and spatial analysis in cloud environments
}

\author{
José Ojeda Zújar ${ }^{*}$ (iD \\ Pilar Paneque Salgado ${ }^{2}$ \\ Esperanza Sánchez Rodríguez ${ }^{3}$ (1) \\ Juan Pedro Pérez Alcántara ${ }^{4}$
}

\section{Resumen}

En el contexto del cuarto paradigma científico, la Geografía cuenta con una oportunidad única para desarrollar nuevas formas de investigación mediante el diseño y uso de herramientas de geovisualización, exploración y análisis de datos espaciales en plataformas cloud, así como para explotar nuevas fuentes de datos. El objetivo de este trabajo es analizar diferentes variables e indicadores del Atlas de distribución de renta de los hogares a nivel municipal para el año 2017, a través del desarrollo de una aplicación web que permite realizar análisis exploratorios de datos espaciales e identificar nuevas hipótesis de trabajo que, finalmente, ayuden a seleccionar y definir las metodologías de análisis. Esta exploración preliminar se basa en las posibilidades de geovisualización multiescalar (geovisores web) y de interacción con los datos en los clientes web, a través del uso de herramientas de filtrado, agrupación o análisis (widgets), así como en las posibilidades de identificación y caracterización de una serie de conglomerados (clústeres), que permiten avanzar en la comprensión de la distribución espacial de la renta y sus fuentes de ingreso en España. Los resultados muestran nuevas tipologías territoriales y patrones espaciales que, además, contribuyen a superar ciertas creencias o 'estigmas' territoriales. Este trabajo quiere ser una primera aportación a un proyecto más amplio sobre patrones espaciales y desequilibrios territoriales en España que, además, pueda contribuir a consolidar una nueva forma de hacer Geografía

Palabras clave: Renta; ingresos; desigualdad; geovisor web; clústeres; España.

\footnotetext{
1 Departamento de Geografía Física y Análisis Geográfico Regional. Universidad de Sevilla, España. zujar@us.es. * Autor para correspondencia

2 Departamento de Geografía, Historia y Filosofía. Universidad Pablo de Olavide, de Sevilla, España. ppansal@upo.es

3 Departamento de Geografía Física y Análisis Geográfico Regional. Universidad de Sevilla, España. esanchez@us.es

4 Departamento de Geografía Física y Análisis Geográfico Regional. Universidad de Sevilla, España. jpperezalcantara@us.es
} 


\begin{abstract}
In the context of the fourth scientific paradigm, geography has a unique opportunity to develop new forms of research through the design and use of geovisualization, exploration, and spatial data analysis tools in cloud platforms, as well as to exploit new data sources. The goal of this research is to analyse different variables and indicators in the Atlas of household income distribution at the municipal level for the year 2017. A web application is developed that enables exploratory analyses of spatial data and the identification of new hypotheses that help select and define the analysis methodologies. This preliminary exploration is based on the possibilities of multiscale geovisualization (web geoviewer) and interaction with the data in web clients through filtering, grouping, or analysis tools (widgets), as well as the possibilities of identifying and characterising a series of clusters which facilitate understanding the spatial distribution of income and its sources in Spain. The results show new territorial typologies and spatial patterns that contribute to overcoming certain beliefs or territorial 'stigmas'. This research is an initial contribution to a broader project on spatial patterns and territorial imbalances in Spain that may also contribute to consolidating a new way of doing geography.
\end{abstract}

Keywords: Income; inequality; web geoviewer; clusters; Spain.

\title{
1. Introducción
}

La ciencia geográfica tiene en estos momentos una excelente oportunidad para demostrar su unicidad y utilidad para hacer aportaciones científicas novedosas que permitan avanzar en un debate informado y riguroso sobre algunos de los grandes desafíos de la sociedad actual. Ello se debe principalmente a que la actual revolución digital —-definida por el big data, los entornos cloud, los geoservicios web o el internet de las cosas- facilita la exploración y análisis de nuevos datos geolocalizados que permiten construir nuevas hipótesis y avanzar en nuevas investigaciones que resulten útiles para la comprensión y la mejor resolución, entre otros, de problemas de interés político y social (Ojeda \& Paneque, 2019).

La oportunidad que brinda el contexto de la denominada 'cuarta revolución industrial' (Brynjolfsson $\&$ McAfee, 2014; Schwab, 2017) es doble. Por una parte, la Geografía cuenta con nuevas herramientas de geovisualización en plataformas cloud, que facilitan no solo representar y visualizar variables de forma dinámica sino también introducir nuevas formas de exploración y análisis de datos. El uso de estas herramientas — que se enmarca en el denominado 'cuarto paradigma científico' (Gray \& Szalay, 2007; Hey, Tansley \& Tolle, 2014) — transforma de manera profunda el análisis tradicional de la información geográfica al permitir que se modifique la secuencia de la investigación, esto es, que las hipótesis deriven de la previa exploración de los datos, lo que resulta, sin duda, un cambio sustantivo. Por otra parte, en este contexto, la Geografía también cuenta con datos masivos (Gutiérrez-Puebla, García-Palomares \& Salas-Olmedo, 2016; Gutiérrez-Puebla, 2018) muy novedosos, que hacen posible investigar realidades menos conocidas o peor comprendidas hasta el momento, lo que resulta, además, una cuestión clave en el debate existente sobre el propio futuro de la ciencia geográfica (Ash, Kitchin \& Leszczynski., 2016; Graham \& Shelton, 2013; Johnston et al., 2014; Kitchin, 2013).

Con este telón de fondo, en este trabajo se podría aludir a una 'Geografía disruptiva' para hacer referencia a esta nueva forma de explorar y analizar datos geográficos, que permite estudiar aspectos territoriales hasta ahora poco estudiados y confirmar o cuestionar ciertas creencias no siempre bien sustentadas. Para ello, en este trabajo se realiza un análisis novedoso, tanto por su detalle espacial como por su enfoque, utilizando los datos ofrecidos por el Atlas de distribución de renta de los hogares —elaborado por el Instituto Nacional de Estadística (INE) y por la Agencia Estatal de Administración Tributaria (AEAT) como parte de sus estadísticas experimentales-, que ejemplifica la nueva información geográfica disponible, antes mencionada, y que no ha recibido atención suficiente por parte de la investigación geográfica española hasta el momento. Con la geovisualización, la exploración y el análisis de estos datos en un entorno cloud se persigue construir nuevas hipótesis sobre la distribución espacial de la renta y sus fuentes de ingreso (salarios, prestaciones y otras rentas) a nivel municipal, así como realizar una primera clasificación y segmentación preliminar del territorio nacional en tipologías que permitan su caracterización a partir de estas variables de renta y sirvan como punto de partida para un análisis posterior más detallado con indicadores de desigualdad y a escalas inframunicipales. 


\subsection{Análisis tradicionales de la distribución de la renta de los hogares en España}

La distribución de la renta es un elemento esencial del bienestar de la población y está directamente ligada al estudio de la desigualdad, cuestión que, tras la última crisis económica y financiera, ocupa un lugar aún más central en la agenda científica y política internacional (Ayala, Martín \& Vicente, 2020; Castells-Quintana, Ramos \& Royuela, 2015; EU, 2019; OECD, 2015). El caso de España es especialmente grave en el contexto europeo: por una parte, desde mediados de los noventa y hasta la crisis de 2007 la desigualdad no se logró reducir a pesar de ser este un periodo caracterizado por una fuerte expansión económica y un intenso crecimiento del empleo. Por otra parte, España se ha visto especialmente afectada por la caída del nivel medio de renta y la acentuación de las desigualdades derivadas de la crisis sufrida a partir de esa fecha (CES, 2013). En concreto, se ha estimado que la renta disponible de los hogares españoles cayó un 20 \% desde 2007 — cuando alcanza un máximo de $28.000 €$ — hasta 2013 y que, además, la distribución de dicha renta ha empeorado (Ayala, 2016; Goerlich, 2016 y 2017), pudiéndose afirmar que las consecuencias de la crisis en términos de pérdida de renta habrían recaído, sobre todo, en los grupos con rentas inferiores (CES, 2013). Esta consolidación de la desigualdad en España contraviene las bases constitucionales ${ }^{5}$ y se convierte en uno de los grandes desafíos tanto de la política estatal como de la europea (OECD, 2020). Así, se han introducido cambios en los criterios de reparto de los fondos comunitarios para el periodo 2021-2027, que se asignarán atendiendo a criterios más integradores —como el desempleo juvenil—, que superan el mero PIB per cápita (EU, 2019).

Hasta el momento, la distribución de la renta se ha estudiado fundamentalmente a través de la Encuesta de Presupuestos Familiares $(E P F)^{6}$ y de la Encuesta de Condiciones de Vida (ECV) ${ }^{7}$, elaboradas por el INE. La EPF permite conocer el gasto en consumo de los hogares, así como la distribución de dicho gasto entre las diferentes parcelas de consumo, a través de una entrevista personal realizada a una muestra de unas 24.000 viviendas. Por su parte, la ECV proporciona información sobre ingresos, pobreza y privación, igualdad, cuidados y otras cuestiones ligadas al nivel de vida y a la cohesión social, y se elabora a partir de entrevistas personales realizadas a los miembros de una muestra de unos 15.000 hogares. Ambas operaciones estadísticas aportan resultados a nivel nacional y de comunidad autónoma de residencia a partir de las citadas selecciones muestrales, lo que hasta el momento ha sido una limitación importante para analizar la distribución de la renta a escalas de mayor detalle.

En relación con el análisis de la desigualdad de la distribución espacial de la renta a partir de fuentes de origen tributario, hay que destacar el trabajo realizado por la AEAT, que elabora la Estadística de los Declarantes del Impuesto sobre la Renta de las Personas Físicas (IRPF) por Municipios ${ }^{8}$, que describe los niveles de renta en el ámbito municipal y ofrece una perspectiva de la renta personal bruta ${ }^{9}$ la renta disponible $^{10}$ de los declarantes de IRPF, aunque solo para los municipios de más de 1.000 habitantes. A este registro se une la Estadística de los Declarantes del IRPF de los Mayores Municipios por Código Postal ${ }^{11}$, también elaborada por la AEAT, que cuenta con un nivel inframunicipal y complementa la operación estadística antes citada para proporcionar un mayor detalle de la renta bruta media y de las magnitudes declaradas a nivel de distrito postal en municipios que cuenten con más de 200.000 habitantes, más de 100.000 declaraciones de IRPF, o bien con una renta bruta agregada superior a 2.200 millones de euros. En este caso, el trabajo de la AEAT supera la limitación de la naturaleza muestral de las encuestas realizadas por el INE, pero cuenta con el inconveniente de que solo recoge datos sobre los declarantes, no contabilizando las rentas percibidas por aquellos que se sitúan por debajo del umbral de declaración. Por

5 Constitución Española. Artículo 40. 1. Los poderes públicos promoverán las condiciones favorables para el progreso social y económico y para una distribución de la renta regional y personal más equitativa, en el marco de una política de estabilidad económica. De manera especial realizarán una política orientada al pleno empleo.

6 Encuesta de Presupuestos Familiares. Metodología. https://www.ine.es/metodologia/t25/t2530p458.pdf

7 Encuesta de Condiciones de Vida. Metodología. https://www.ine.es/daco/daco42/condivi/ecv_metodo.pdf

8 Estadística de los Declarantes del IRPF por Municipios. Metodología. https://www.agenciatributaria.es/AEAT.internet/datosabiertos/ catalogo/hacienda/Estadistica_de_los_declarantes_del_IRPF_por_municipios.shtml

9 Renta bruta: Es la renta agregada antes de impuestos de los declarantes sin reducciones fiscales incluyendo la renta exenta, lo que confiere a esta variable un carácter atemporal e independiente de la normativa tributaria que resulte de aplicación en cada uno de los ejercicios fiscales.

10 Renta disponible: Es la renta bruta después de impuestos, considerando éstos en sentido amplio al integrar la parte de las cotizaciones sociales del trabajo por cuenta ajena y la cuota resultante de la declaración.

11 Estadística de los Declarantes del IRPF de los Mayores Municipios por Código Postal. Metodología. https://www. agenciatributaria.es/AEAT/Contenidos_Comunes/La_Agencia_Tributaria/Estadisticas/Publicaciones/sites/irpfCodPostal/2016/ docf3b3clla0ea48f9b357661c74ab2d9392f0c5011c.html 
último, hay que resaltar el trabajo realizado por la Fundación de Estudios de Economía Aplicada (FEDEA $)^{12}$ para la construcción de la base de datos sobre la renta personal de los municipios españoles y su distribución (series 2004-2007 y 2011-2014), que parte de las muestras anuales de microdatos de IRPF elaboradas por la AEAT para realizar estimaciones de la renta personal ${ }^{13}$ y su desigualdad y concentración a nivel local en municipios de más 5.000 habitantes.

Estas fuentes han permitido hacer análisis longitudinales de interés, que confirman la reducción de la renta media y el incremento de la desigualdad (Anghel et al., 2018; Ayala, 2016; Ayala \& Cantó, 2020; Hortas \& Onrubia, 2020). No obstante, estas fuentes presentan limitaciones al no permitir realizar análisis a escala municipal para poder conocer de manera detallada cuál es la distribución de la renta según las fuentes de ingreso (Hortas \& Onrubia, 2014, 2020; Hortas \& Ríos, 2019). Esta cuestión resulta nuclear ya que el aumento del desempleo, el crecimiento del empleo temporal, el descenso de los niveles salariales, los bajos salarios mínimos y la creciente brecha entre los salarios más altos y los más bajos se han identificado como los factores más relevantes a la hora de explicar la desigualdad en España (Ayala \& Cantó, 2020; CES, 2013; Davia, 2014; FOESSA, 2015; Goerlich, 2016, 2017; Larraz, Pavía \& Herrrera, 2020).

\subsection{Hipótesis de partida, objetivos específicos y área de estudio}

En este trabajo se parte de tres hipótesis que se corresponden con los objetivos específicos que articulan esta investigación:

a. El Atlas de distribución de renta de los hogares (ADRH) constituye una fuente de información novedosa, cuyos datos permiten realizar un avance sustantivo en el estudio de la distribución espacial de la renta y en el análisis de la desigualdad territorial. Así, el primer objetivo de este trabajo es la exploración y presentación de esta nueva fuente de información y las variables que incorpora a nivel municipal.

b. Las nuevas tecnologías geográficas y los entornos cloud permiten la utilización de herramientas web interactivas (geovisores, widgets, dashboard) que posibilitan una geovisualización rápida, multiescalar y una eficiente exploración y análisis de los datos. Aunque se ha avanzado en la construcción de geovisores web por parte de la AEAT y del INE, así como del propio ADRH ${ }^{14}$, es cierto que estos siguen presentando clientes para la geovisualización poco dinámicos e interactivos y con limitadas opciones de consulta, filtrado y análisis. Por lo tanto, la propuesta metodológica en este trabajo presenta un aspecto claramente diferenciador: la incorporación a la propia geovisualización (geovisor web) de herramientas gráficas interactivas (widgets) que filtran o agrupan espacialmente los datos visualizados en tiempo real, además de otras herramientas de análisis espacial que permiten realizar una exploración preliminar exhaustiva y personalizada de esos datos antes de establecer las hipótesis de trabajo. Esto supone, efectivamente, un cambio sustancial respecto al análisis espacial clásico en el que el mapa final, de carácter estático, constituía el resultado final de un proceso investigador. Por tanto, el segundo objetivo del trabajo es la exploración preliminar de los datos a través del desarrollo de aplicaciones web (geovisores, widgets y dashboards) de acceso público, ajustándose a los presupuestos de ciencia abierta, lo que ya es en sí mismo un resultado de la investigación y permite, además, explorar con más detalle posibles hipótesis de trabajo y las metodologías por aplicar en la fase de análisis.

c. Partiendo de esta exploración preliminar de los nuevos datos de la renta de los hogares a escala municipal podría lograrse una mejor compresión inicial de su distribución espacial con el uso de clasificaciones en tipologías territoriales (clústeres), construidas a partir de las variables identificadas como más representativas en dicha exploración. Así, el tercer objetivo no es otro que avanzar en el conocimiento sobre la distribución de la renta de los hogares y las fuentes de ingreso, así como construir nuevas hipótesis de trabajo, derivadas de este primer análisis de conglomerados, que serán contrastadas en próximas investigaciones.

12 Renta personal de los municipios españoles y su distribución. https://www.fedea.net/renta/

13 Renta personal: incluye información sobre renta imponible agregada, renta media per cápita y por declarante de IRPF y renta mediana. 14 Visor de mapas del ADRH. https://inespain.maps.arcgis.com/apps/MinimalGallery/index.html?appid=c8b4lb2c471845afbc8f8eb20c 54382e\# 
El trabajo que ahora se presenta, de acuerdo con el alcance de los datos del ADRH (INE, 2019, 2020a), se ha llevado a cabo a nivel municipal para el año 2017 y en la totalidad del Territorio de Régimen Fiscal Común, que excluye a la población domiciliada en el País Vasco y Navarra ${ }^{15}$. Además, por la aplicación de las normativas de privacidad de datos, quedan fuera del análisis los municipios de menos de 100 habitantes. De esta forma, en este trabajo se analizan datos de 6.308 municipios.

\section{Metodología}

\subsection{Datos temáticos}

El ADRH supone un avance sustantivo respecto a las fuentes antes comentadas para el estudio de la distribución de la renta. Desarrollado en el marco de la estadística experimental y formando parte del Sistema Estadístico Europeo ${ }^{16}$, permite el análisis municipal e inframunicipal (secciones censales) a partir del enlace de información de población del INE — que forma parte de los trabajos previos al Censo de Población y Viviendas 2021 - con datos tributarios de la AEAT ${ }^{17}$. Sin duda, se trata de la fuente de datos publicados sobre renta de naturaleza censal (no muestral) con la mayor desagregación a nivel municipal, lo que la hace especialmente adecuada para el análisis espacial. En la Figura 1 se presenta la distribución de la renta media por persona de acuerdo con el alcance geográfico de los datos de la AEAT y del ADRH, respectivamente, pudiéndose observar el avance, en términos de cobertura territorial, que introducen los datos analizados en este trabajo.

Figura 1. Cobertura y distribución territorial de los datos de renta media municipal a partir de los datos tributarios de la AEAT (a) y de los datos del ADRH (b), 2017

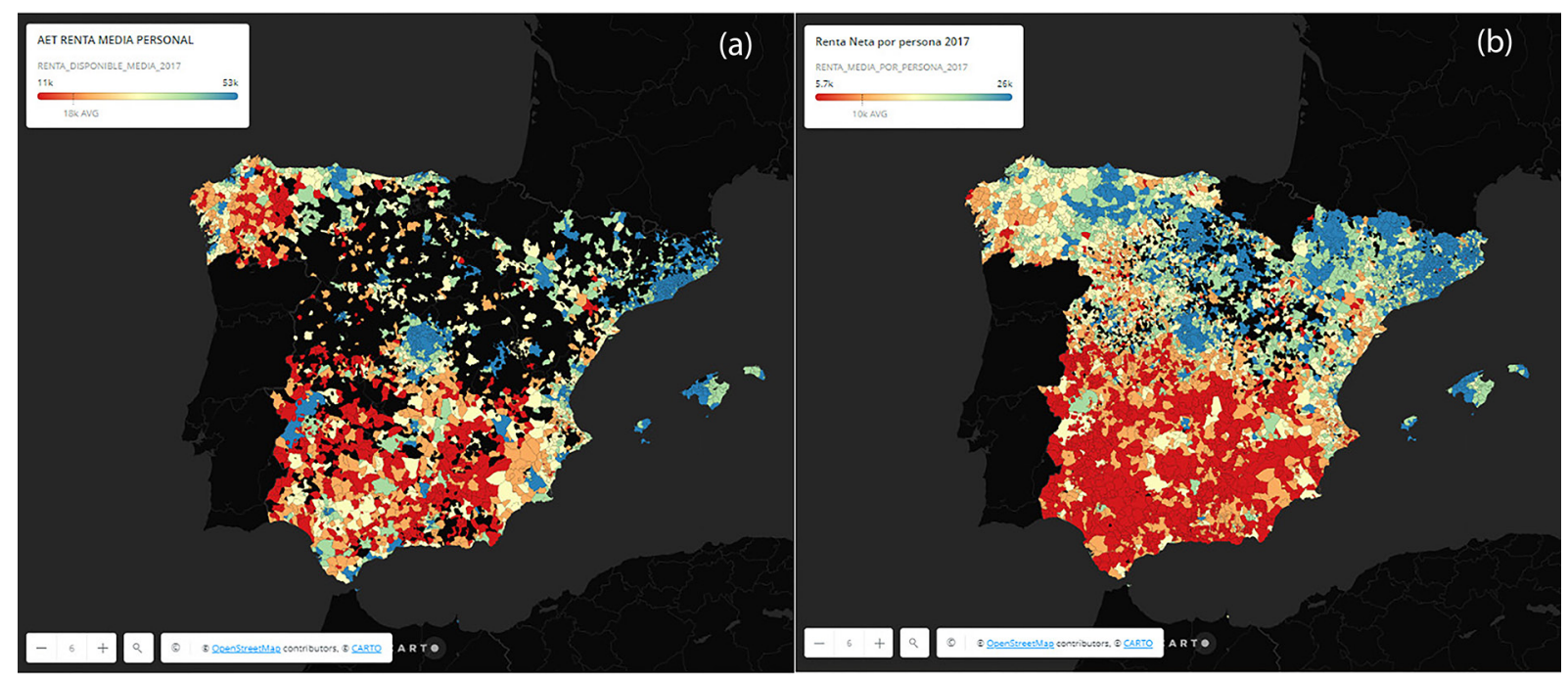

Fuente: AEAT, INE. Elaboración propia. Imágenes extraídas de la aplicación web desarrollada

Además de ofrecer una mayor cobertura territorial, los datos del ADRH superan la limitación que supone el carácter muestral de las encuestas sobre renta realizadas por el INE (las ya comentadas EPF y ECV), así como la limitación para el análisis de la desigualdad de los trabajos previos realizados por la AEAT que solo incluyen a los declarantes del IRPF. Como se verá en las siguientes secciones de este trabajo, el hecho de contar con información de renta de los no declarantes (aquellos que se sitúan por debajo del umbral de declaración), así como con información de las distintas fuentes de ingreso e indicadores de desigualdad, otorga al ADRH y al trabajo que aquí se presenta de un carácter original en relación con los análisis desarrollados hasta el momento.

15 Hasta la última actualización de diciembre de 2020, el ADRH excluía a País Vasco y Navarra, dado que no se disponía de información de distribución de renta de las cuatro Haciendas Forales (Bizcaia, Gipuzcoa, Álava y Navarra). En la actualización realizada en esa fecha, la información se amplía al incorporar datos de algunas Haciendas Forales.

16 European Statistical System (ESS). Experimental Statistics. https://ec.europa.eu/eurostat/web/ess/experimental-statistics

17 Atlas de distribución de renta de los hogares (ADRH). Proyecto técnico. Diciembre 2020. https://www.ine.es/experimental/atlas/exp_ atlas_proyecto.pdf 
Como novedad de su última edición (de 20 de diciembre de 2020), el ADRH ha incorporado, para los años 2015, 2016 y 2017 (a nivel de sección censal, distritos y municipios) distintos indicadores de renta media y mediana por persona y hogar, renta bruta media por persona y hogar, distribución por fuentes de ingreso (hasta finales de 2020 en porcentaje y desde diciembre de 2020 en euros), el porcentaje de población con ingresos por unidad de consumo inferiores o superiores a determinados niveles de renta ${ }^{18}$, así como el indicador de distribución de la renta P80/P20 (cociente entre el percentil 80 y el 20) y el índice de Gini. Igualmente, de forma complementaria, incorpora una serie de indicadores demográficos elaborados a partir del fichero precensal de población de cada año; en particular: la edad media de la población, los porcentajes de población menor de 18 años y mayor de 65 años, el tamaño medio del hogar, el porcentaje de hogares unipersonales y la población residente en viviendas familiares.

En este trabajo se analizan, a nivel municipal, y exclusivamente para el año 2017, los siguientes indicadores (Figura 2):

a. La renta bruta y neta media por persona, definida como la suma en un ámbito geográfico de todas las rentas brutas y netas encontradas ${ }^{19}$ dividido entre el total de personas "encontradas" que residen en ese ámbito geográfico; y la renta neta y bruta media por hogar (Figura 2a), definida como la suma en un ámbito geográfico de todas las rentas brutas y netas asociadas a hogares encontradas, dividido entre el total de hogares encontrados de ese ámbito geográfico ${ }^{20}$.

b. Distribución de la renta bruta media por fuentes de ingreso (en \%, de acuerdo con la metodología de INE, 2019; y en euros, de acuerdo con la de INE, 2020a), definida como la suma en un ámbito geográfico de todos los ingresos procedentes de la fuente en cuestión dividido entre la suma de todos los hogares o personas "encontrados" en ese ámbito. De las tres fuentes de ingreso diferenciadas por la AEAT —salarios; prestaciones (pensiones, desempleo, otras prestaciones); y otras rentas (del capital, de la renta de inmuebles, etc.) - el ADRH distingue cinco categorías (Figura 2b-f):

- Salarios: salarios, aportación del empleador a planes de pensiones y seguros colectivos, indemnizaciones por despido y trabajos en el extranjero.

- Pensiones: pensiones de jubilación, que incluye mayoritariamente las pensiones de viudedad, junto con las pensiones por jubilación ordinaria, anticipada y otras.

- Prestaciones de desempleo: Prestaciones por desempleo sujetas y prestaciones por desempleo exentas.

- Otras prestaciones: renta de emancipación y otras prestaciones exentas (prestaciones de incapacidad, prestaciones de dependencia, prestaciones familiares, becas exentas, otras prestaciones exentas y deducciones familiares).

- Otros ingresos: rentas del capital mobiliario, rentas por arrendamiento de inmuebles, rendimientos de actividades económicas, renta imputada y otras (renta inmobiliaria imputada y otras rentas de regímenes especiales).

En las seis imágenes de la Figura 2 puede comprobarse, a simple vista, la presencia de evidentes patrones espaciales en la distribución de la renta bruta media por hogar y sus fuentes de ingreso. Por otra parte, los datos de la Tabla 1 constatan que las fuentes que más contribuyen proporcionalmente a las rentas brutas medias municipales en relación con los ingresos de mercado son los salarios (con medias del $52 \%$ y $6.363 €$ ) y las que realizan una contribución mayor en relación con las prestaciones son las pensiones (con medias del $27,7 \%$ y $3.255 €$ ).

18 i) Porcentaje de población con ingresos por unidad de consumo por debajo de determinados umbrales fijos (5.000, 7.500, 10.000); y, ii) Porcentaje de población con ingresos por unidad de consumo por debajo de determinados umbrales relativos expresados como porcentaje de la mediana (umbrales considerados, obtenidos a partir de la propia distribución de los ingresos por unidad de consumo: $40 \%, 50 \%, 60 \%, 140 \%, 160 \%$ y $200 \%$ de la mediana). Además, para estos indicadores se ofrecen también datos desagregados por sexo, grupos de edad (menores de 18 años, de 18 a 64 años, de 65 y más años) y la nacionalidad (españoles, extranjeros), pudiéndose cruzar la variable sexo con tramos de edad y nacionalidad.

19 Se considera que un hogar se ha "encontrado" si aparece información de renta para alguno de sus miembros en alguno de los modelos de la AEAT utilizados por el ADRH. Una persona se considera "encontrada" si reside en un hogar encontrado (INE, 2020a).

20 En la actualización del ADRH, de 20 diciembre de 2020, la información primaria del indicador renta neta del hogar proviene de distintos formularios de la AEAT y, a diferencia de la ECV, incluye las retribuciones en especie y las rentas imputadas. 
Figura 2. Distribución espacial de la renta bruta media por hogar (a) y de las fuentes de ingreso (\%), 2017: salarios (b), otros ingresos (c) y prestaciones — desempleo (d), pensiones (e) y otras prestaciones (f)-
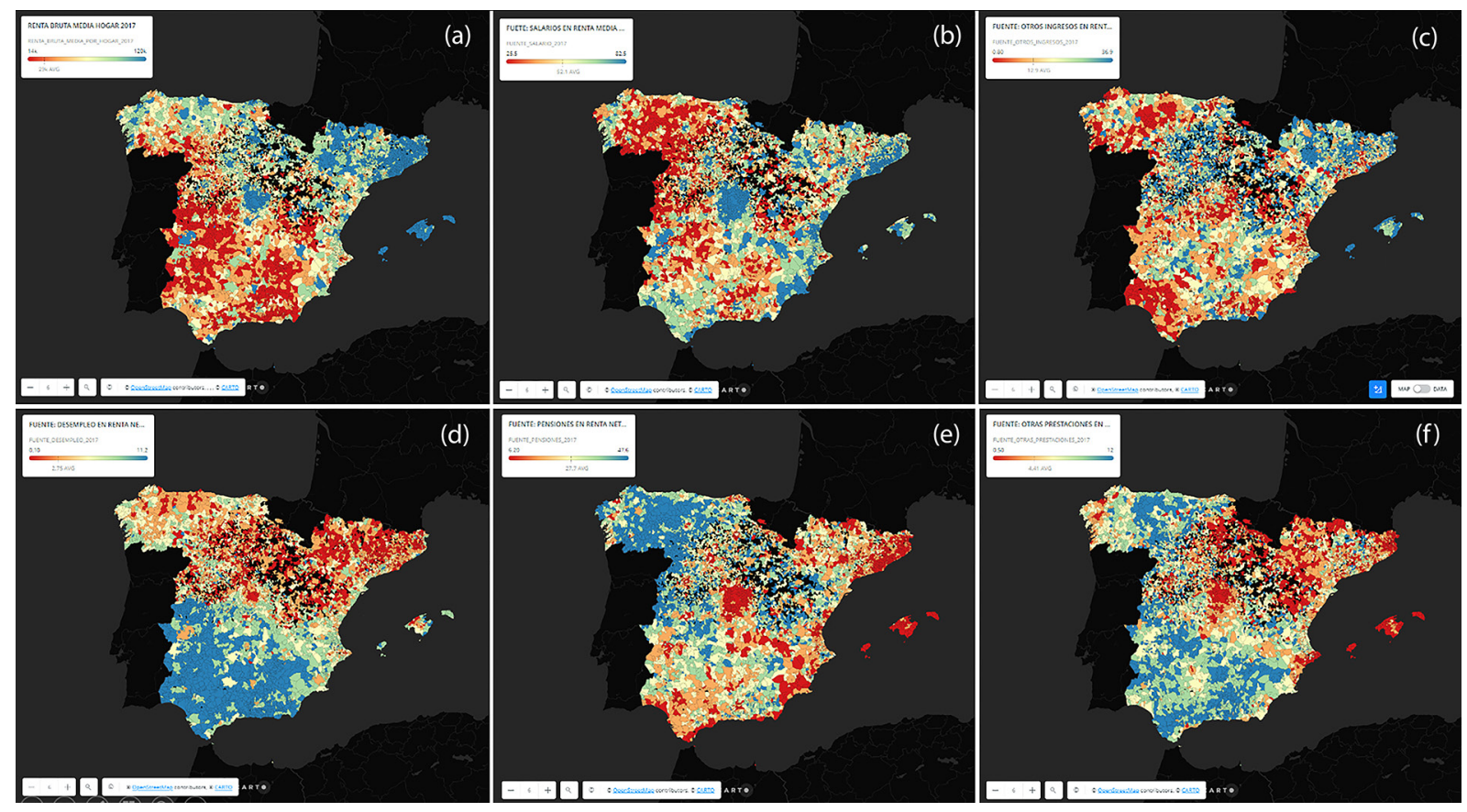

Fuente: INE. Elaboración propia. Imágenes extraídas de la aplicación web desarrollada

Tabla 1. Contribución de las fuentes de ingreso a las rentas brutas medias (\%) y la renta bruta media por persona (€), 2017

\begin{tabular}{|l|l|c|c|c|c|}
\hline \multicolumn{2}{|c|}{$\%$} & Media & Desv. Est. & Mínimo & Máximo \\
\hline \multirow{4}{*}{ Mercado } & Salarios & 52,1 & 10,7 & 25,5 & 82,5 \\
\cline { 2 - 6 } & Otros ingresos & 12,9 & 5,4 & 0,8 & 36,9 \\
\hline \multirow{4}{*}{ Prestaciones } & Pensiones & 27,7 & 8,7 & 6,2 & 47,6 \\
\cline { 2 - 6 } & Otras prestaciones & 4,4 & 1,9 & 0,5 & 12,0 \\
\cline { 2 - 6 } & Desempleo & 2,8 & 2,0 & 0,1 & 11,2 \\
\hline \multirow{3}{*}{ Mercado } & $€$ & Media & Desv. Est. & Mínimo & Máximo \\
\hline \multirow{3}{*}{ Prestaciones } & Salarios & 6.363 & 2.332 & 1.562 & 23.471 \\
\cline { 2 - 6 } & Otros ingresos & 1.698 & 943 & 60 & 14.134 \\
\cline { 2 - 6 } & Oensiones & 3.255 & 1.065 & 745 & 7.845 \\
\cline { 2 - 6 } & Desempleo & 297 & 152 & 62 & 839 \\
\hline
\end{tabular}

Fuente: INE. Elaboración propia

\subsection{Datos espaciales y geometría}

La geometría de los municipios se ha obtenido del Centro de Descargas del Centro Nacional de Información Geográfica ${ }^{21}$ (formato shapefile) que, para la escala municipal, proporciona la geometría de la España peninsular, Ceuta, Melilla y Baleares, separados de los de Canarias y referida a sistemas de referencia de coordenadas geográficas diferentes (ETRS89 y WGS84, respectivamente). La geometría de los municipios se corresponde con su distribución en julio de 2019. 


\subsection{Tratamiento de datos y generación de una base de datos espacial}

El volumen de datos a manejar para integrar todas las variables del ADRH —no solo los municipales utilizados en este artículo- ha exigido la incorporación y modelado de las mismas en una base de datos espacial, que no solo es necesaria como un elemento básico de la aplicación web desarrollada, sino que también permitirá establecer controles de calidad para la validación de los datos con el uso de sentencias SQL, además del cálculo de nuevas variables.

Todas las variables e indicadores del ADRH utilizados se modelaron e importaron como tablas al gestor de bases de datos espacial PostgreSQL/PostGIS y, para este trabajo, se han extraído exclusivamente los datos referidos a los municipios mediante una consulta SQL basada en la longitud del campo que contiene el código ${ }^{22}$, obteniéndose una tabla por conjunto de indicadores de renta media, fuentes de ingreso e indicadores demográficos.

Por su parte, la geometría de los municipios (descargada originalmente en formato shapefile) se ha normalizado pasando todos los polígonos municipales al sistema de referencia de coordenadas WGS84, ya que será este el que utilice la aplicación web. Posteriormente, se ha importado este shapefile a la base de datos PostgreSQL/PostGIS ${ }^{23}$, generando una tabla que contiene los códigos INE del municipio y la provincia, así como los nombres del municipio, la provincia y la comunidad autónoma, además de la geometría que define los municipios (Multipolygon). Los datos de renta se han asignado a la geometría de cada municipio mediante una consulta SQL que une ambas tablas a través del campo del código INE del municipio, que ambas comparten. De esta forma se dispone de tres tablas con referencia espacial, una por cada grupo de indicadores.

Para evaluar la calidad de los datos se han realizado consultas SQL para identificar tanto entidades espaciales para las que no se dispone de datos de renta como la posible existencia de datos de renta que no se hubieran podido asignar a ninguna entidad con geometría. En el primer grupo se han identificado siete municipios, todos en Andalucía ${ }^{24}$, que se corresponden con segregaciones aprobadas en octubre de 2018. La falta de datos se debe, por tanto, a su inexistencia en las fechas para las que se dispone de indicadores (2015, 2016 y 2017), de manera que estos polígonos se han debido unir a los que representan los municipios de los que se segregaron. Por otra parte, no se ha podido constatar la existencia de datos de renta que no se puedan asignar a ninguna entidad existente en la tabla de municipios.

\subsection{Generación y diseño de una aplicación web para la exploración y visualización de los datos en un entorno cloud}

Para realizar la geovisualización, la exploración, el análisis y la descripción de la distribución espacial de los datos del ADRH se ha desarrollado una aplicación web que incluye una serie de clientes ligeros en un entorno cloud (geovisores, widgets y dahsboards), que responde a una de las prioridades de la Unión Europea en materia de ciencia abierta ${ }^{25}$, esto es, facilitar el acceso, la explotación y la difusión de los resultados de la investigación a través de internet. Como parte de esta aplicación web se han desarrollado cinco geovisores y una serie de componentes dinámicos e interactivos (widgets) integrados en distintos dashboards, que facilitan la visualización de salidas gráficas y cartográficas de los datos analizados - tanto a expertos como a la población en general, lega en la materia, siendo esta una de sus principales ventajas-, así como la personalización de las consultas a través de la selección de variables y de una serie de filtros que se resuelven en tiempo real (rango de los valores de las variables, valores máximos y mínimos de cada variable, etc.). La opción del filtrado de información permite la creación de multitud de visualizaciones a partir de una sola capa de información y el análisis de solo aquellos datos que sean objeto de estudio. En concreto, en este trabajo se utiliza la herramienta Builder de la plataforma cloud de la empresa CARTO ${ }^{26}$.

\subsection{Análisis de conglomerados (clústeres)}

La exploración previa de los datos a través de los widgets, desarrollados e integrados junto al geovisor web, sirve de punto de partida para realizar un conjunto de análisis de conglomerados, como nuevos ele-

22 El código municipal consta de 5 caracteres, el de los distritos de 7 y el de las secciones de 10.

23 Mediante la aplicación PostGIS Bundle 3 for PostgreSQL x64 12 Shapefile and DBF Loader Exporter.

24 San Martín del Tesorillo, Fuente Carreteros, La Guijarrosa, Fornes, Torrenueva Costa, La Zarza-Perrunal y El Palmar de Troya.

25 European Open Science Cloud (EOSC). https://ec.europa.eu/research/openscience/index.cfm?pg=open-science-cloud

26 CARTO Builder. https://carto.com/builder/ 
mentos de análisis exploratorio preliminar de los datos espaciales, con el que se quiere responder al tercer objetivo específico de este trabajo: realizar un conjunto de clasificaciones y una caracterización tipológica de los territorios en función de la distribución de la renta bruta media a escala municipal según las fuentes de ingresos (tanto en su expresión en porcentaje como en euros), a partir de los datos del ADRH. Con ello se persigue la identificación de una serie de clústeres - a modo de primeras taxonomías espaciales—, que cumplan la condición de que los datos observados en cada uno de ellos sean lo más homogéneos posible en cuanto a las variables analizadas (porcentaje de renta obtenida por cada una de las cinco categorías de fuentes de ingreso o su expresión en euros), al tiempo que cada clúster quede lo más claramente diferenciado del resto respecto a esas mismas variables. Existen muchos tipos de análisis de conglomerados en el contexto del análisis multivariable; en este caso se ha utilizado un tipo análisis de conglomerados integrado en ArcGIS 10.8 $8^{27}$, con el que se pretende obtener una primera tipología de conglomerados 'naturales', en línea con el objetivo de este artículo de hacer una primera presentación de esta fuente de datos y valorar su potencialidad. Se ha elegido esta opción con la intención de realizar un análisis multivariable clásico sin incorporar ninguna variable espacial en su análisis (no_spatial_constraint) y con una selección aleatoria de los elementos a partir del que comienzan los procesos de asignación a los clústeres (random seeds). Al seleccionar la opción no_spatial_constraint, para el agrupamiento se utiliza un algoritmo de K-medias.

En segundo lugar, y de forma complementaria, se ha realizado un análisis de clúster y outlier ${ }^{28}$, utilizando el índice de 'I Anselin local de Moran' para el indicador de renta neta media por persona —en este caso, comparando los resultados obtenidos con diferentes definiciones de vecindad tanto en ArcGIS 10.8 $(150 \mathrm{~km})$ como en la herramienta que para este análisis ofrece la propia plataforma de CARTO (5 vecinos) - , con el objetivo de incorporar la influencia de esta variable espacial (la proximidad/contigüidad de los recintos de los municipios vecinos a cada municipio) en la distribución del valor de la renta neta media por persona a nivel municipal. El resultado de este análisis es un conjunto de conglomerados con continuidad espacial que identifica agrupaciones de puntos calientes (municipios con valores altos rodeados de altos, municipios con valores bajos rodeados de bajos) y valores atípicos (altos rodeados de bajos y bajos rodeados de altos). Las tablas con los resultados de estos análisis se incorporan posteriormente a la base de datos espacial y se relacionan con el resto de las variables por la presencia en las tablas de resultados del código INE de cada municipio, lo cual permitirá su geovisualización, así como la interacción con el resto de los indicadores a través de los widgets de la aplicación web.

\section{Resultados}

\subsection{Aplicación web para la geovisualización, exploración interactiva y análisis}

Los resultados de la aplicación web se concretan en una serie de enlaces a diferentes clientes web (geovisores y dashboards) que permiten una exploración espacial y gráfica de los datos. El producto utilizado de la plataforma cloud de CARTO (Builder) permite a los usuarios de la plataforma, en primer lugar, la creación de tablas en el gestor de bases de datos espacial PostgreSQL/PostGis (en el back-end de la aplicación web), con un simple plug and play de los datos a analizar, facilitando la importación de estos en distintos formatos (Excel, Shapefile, GeoJson, Geopackage, etc.), o bien con el acceso a una base de datos remota. En este caso, como se ha explicado anteriormente, se ha creado una base de datos con el mismo gestor de base de datos, lo que ha permitido realizar los controles de validación en el propio gestor y ha facilitado su conexión a la plataforma.

Una vez integrada la base datos municipal con los indicadores seleccionados en la plataforma de CARTO, la herramienta Builder permite numerosas posibilidades para la geovisualización (generación de semiología, agregación de la información puntual a estructuras teseladas multiescalares, animación de series temporales, etc.), la exploración interactiva (utilización de widgets categóricos, de histogramas, de fórmulas o de series temporales) y el análisis de los datos (superposición, filtrado, generación de clústeres, etc.). Tras decidir cómo visualizar los datos (semiología), el tipo de widgets (categóricos, de histograma, etc.) a utilizar para su exploración, agrupación y filtrado interactivo o el análisis a aplicar a los mismos, su publicación en internet a través de un cliente ligero es directa y automática, sin que se requiera el uso de

\footnotetext{
27 Herramienta grouping dentro de conjunto de herramientas de análisis estadístico espacial; ver: https://desktop.arcgis.com/es/arcmap/ latest/tools/spatial-statistics-toolbox/grouping-analysis.htm

28 https://desktop.arcgis.com/es/arcmap/latest/tools/spatial-statistics-toolbox/cluster-and-outlier-analysis-anselin-local-moran-s.htm
} 
código. Para este trabajo se han generado cinco clientes ligeros - como ejemplo de algunas de las posibilidades que permite el tratamiento de esta fuente de información en entornos cloud-que se convierten en el principal resultado, ofrecido en abierto, de la investigación.

Los clientes web están orientados a la exploración preliminar de los datos y, por lo tanto, la geovisualización cartográfica es dinámica, a diferencia de los mapas analógicos estáticos o algunos geovisores web con servicios de mapas clásicos; es decir, la semiología (cuantiles, intervalos iguales, etc.) y la leyenda (rango de valores) se recalculan cada vez que se utiliza cualquier widget para filtrar los datos. Por otra parte, utiliza la proyección WGS84 Web Mercator (EPGS 3857) y la escala de visualización se adecua a los niveles de zoom genéricamente utilizados en la mayor parte de las aplicaciones de web mapping y los principales proveedores de mapas en línea (OpenStreetMap, Google, Mapbox, ESRI, etc.). Finalmente, cuando se activa una capa en el geovisor web, se activan los widgets que interactúan con ella (filtrado, agregación, etc. ${ }^{29}$. Esta característica es crítica para la exploración preliminar de los datos espaciales y es uno de los rasgos que diferencia este visor del ofrecido por el propio ADRH, antes mencionado.

A continuación, se presentan las características de los cinco clientes, cuyo acceso se realiza a través de un hipervínculo sobre el nombre de cada uno de ellos y, para obtener información complementaria sobre los mismos, se puede acceder igualmente a través de la página web https://www.geo-patterns.es/:

a. Cliente 1: presenta algunos de los indicadores utilizados en este trabajo, es decir, la renta neta y bruta media por hogar y persona, así como los porcentajes de las fuentes de ingreso (salarios, pensiones, desempleo, otras prestaciones y otros ingresos) para su geovisualización (leyenda y semiología). Cada una de las variables lleva asociado un widget de histograma que permite la selección y filtrado de cada una de estas variables individualmente y, además, la capa renta bruta media por hogar puede interaccionar con los cinco widgets de fuentes de ingreso y con dos widgets categóricos que permiten la agregación y filtrado espacial a nivel de provincia y de comunidad autónoma (Figura 3).

Figura 3. Cliente 1

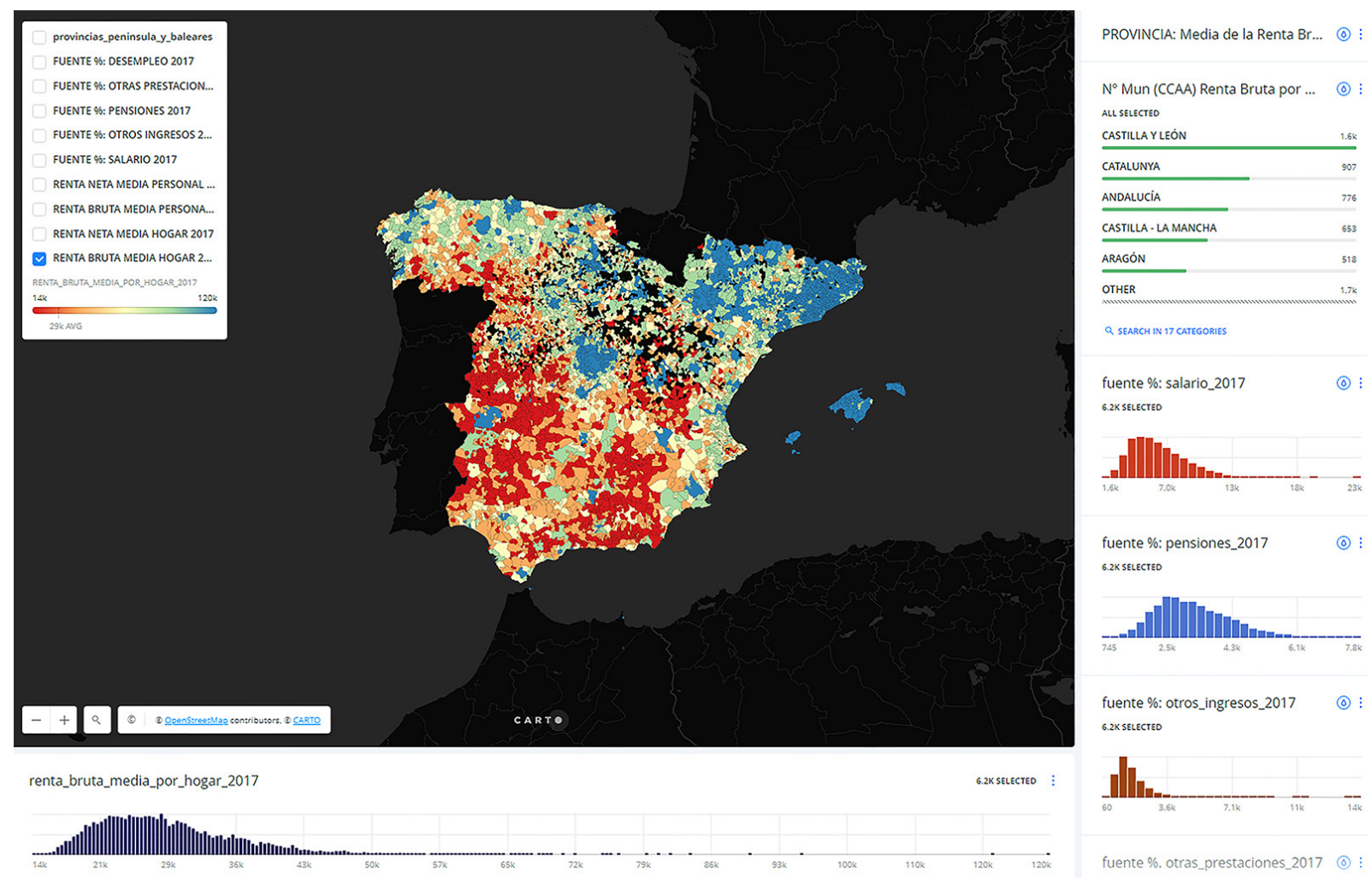

Fuente: AEAT, INE. Elaboración propia. Imagen extraída de la aplicación web desarrollada

29 Para optimizar su uso y posibilidades consultar el siguiente enlace. https://carto.com/help/tutorials/using-builder/\#widgets 
b. Cliente 2: muestra los mismos indicadores de rentas medias y, este caso, se sustituyen las capas de fuentes en porcentaje por las fuentes expresadas en euros para su geovisualización interactiva y su exploración individual con su widget de histograma correspondiente. Además, se introduce la posibilidad de que todos los widgets de fuentes de ingreso (tanto en \% como en $€$ ) y los widgets categóricos que agregan por comunidades autónomas y provincias interactúen con una misma capa que, en este cliente, es la renta media bruta por persona. Con ello, se amplía el potencial de exploración preliminar de los datos. Así, a modo de ejemplo, en la Figura 4 se muestra la posibilidad de comparar datos entre dos comunidades autónomas (seleccionándolas en el widget categórico correspondiente), actualizándose en tiempo real la expresión gráfica y los valores (histogramas) de las cinco variables de distribución de las fuentes de ingreso en euros.

Figura 4. Cliente 2

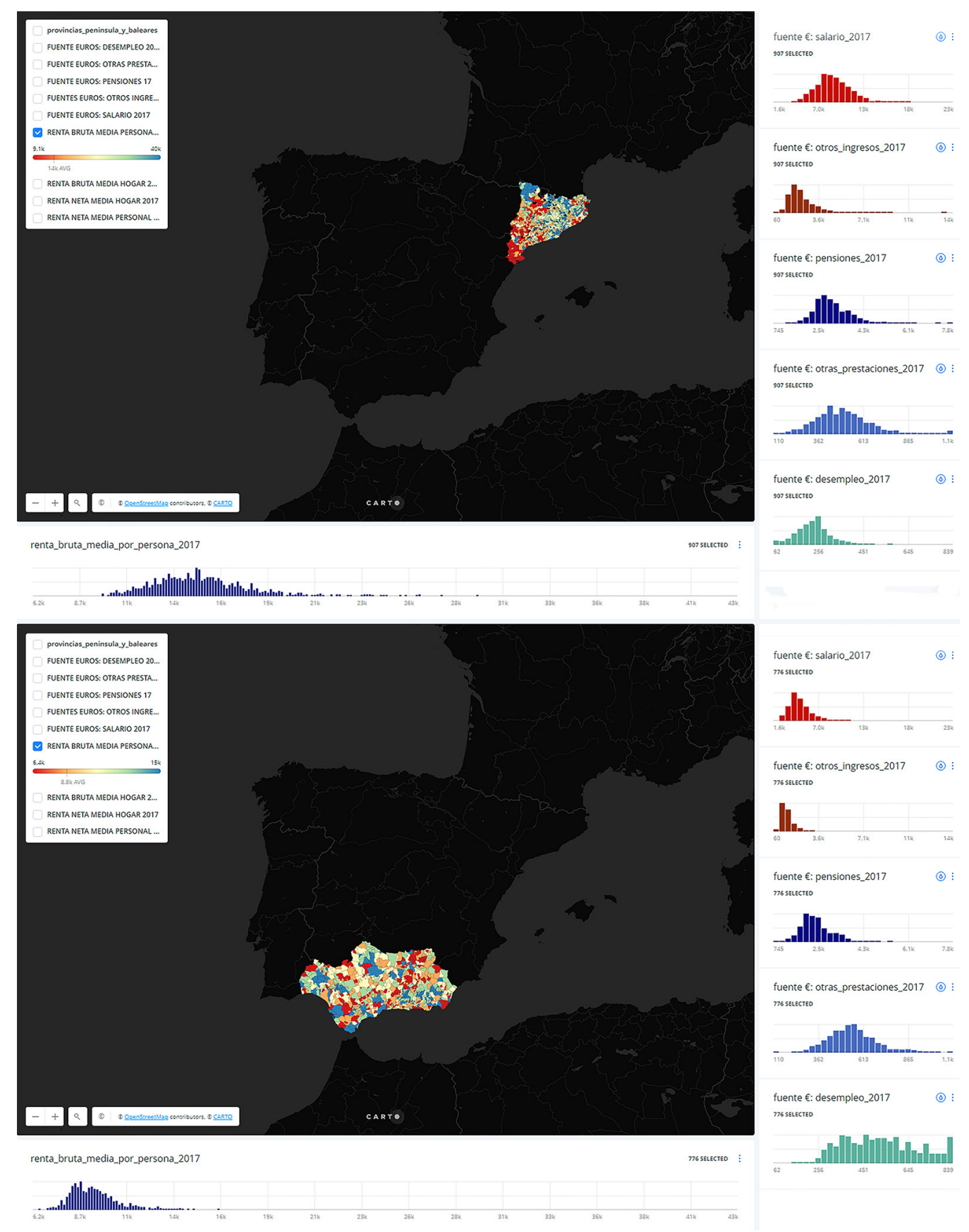

Fuente: AEAT, INE. Elaboración propia. Imágenes extraídas de la aplicación web desarrollada 
c. Cliente 3: este cliente (Figura 5) recoge los resultados del análisis de conglomerados (clústeres) que se explican en el siguiente epígrafe (3.2). La visualización de la capa renta bruta media por persona lleva asociada: i) un conjunto de widgets de histogramas para su filtrado, uno por cada variable de fuentes, tanto en porcentaje como en euros; ii) widgets categóricos para cada uno de los clústeres creados (uno con fuentes en porcentaje y otro en euros), permitiendo el filtrado y la agregación con las clases de cualquiera de ellos; y, iii) otros dos widgets para la agregación espacial por comunidades autónomas (número de municipios) o provincias (renta neta media). Igualmente se incluyen las capas que representan los dos resultados del análisis de clúster y outliers (local I Moran) realizados con el indicador de renta neta media por persona, la cual puede ser filtrada por widgets categóricos de comunidades autónomas y provincia. Finalmente, se han incorporado dos capas calculadas: el sumatorio en euros de todas las prestaciones (pensiones + desempleo + otras prestaciones) y la resta en euros de la principal fuente de ingreso del mercado menos la principal fuente de prestaciones (salarios - pensiones).

Figura 5. Cliente 3
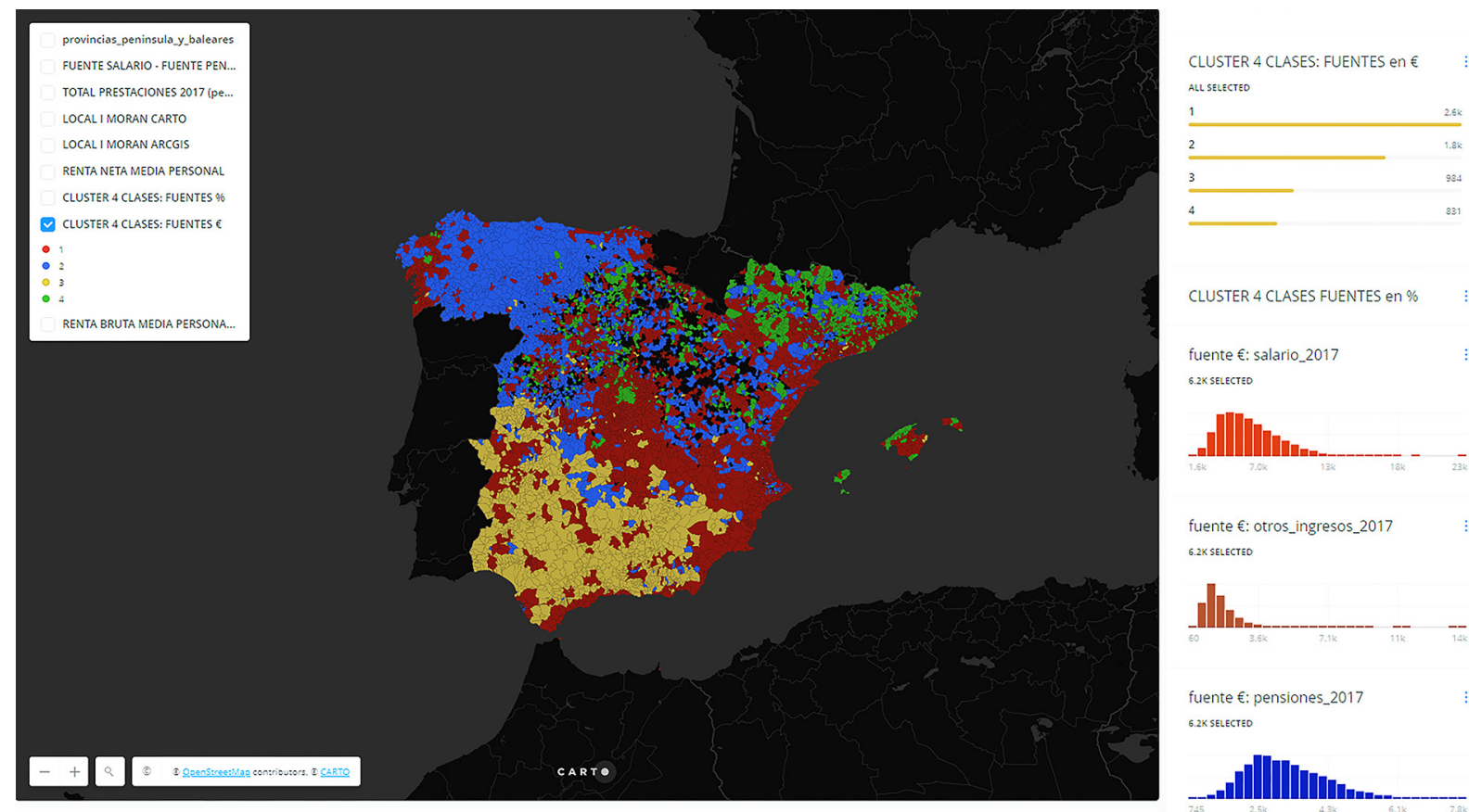

renta_bruta_media_por_persona_2017

6.2K SELECTED :

fuente €: otras_prestaciones_2017 6.2.2 stikcrso
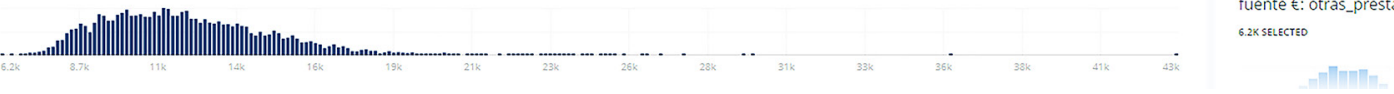

Fuente: AEAT, INE. Elaboración propia. Imagen extraída de la aplicación web desarrollada

d. Cliente 4: este cliente recoge las variables de renta bruta y neta medias por persona, así como algunas variables demográficas explicativas (edad media, porcentaje de jóvenes y mayores, etc.) para su geovisualización, cada una con su widget de histograma correspondiente para su filtrado. Además, la capa renta neta media por persona interacciona con todos los widgets de histograma de las variables demográficas para su filtrado, con dos widgets categóricos que permiten agregar y filtrar por provincias y comunidades autónomas, así como con los dos widgets correspondientes a las clases de los clústeres calculados (Figura 6).

Junto a estos cuatro clientes, que sintetizan los resultados presentados en este artículo, en el Cliente 5 se incorporan nuevas formas de visualización más dinámicas (animaciones) o ejemplos de agregación en teselas multiescalares de tipo hexagonal que amplían el potencial de geovisualización que permiten los nuevos entornos cloud. 
Figura 6. Cliente 4
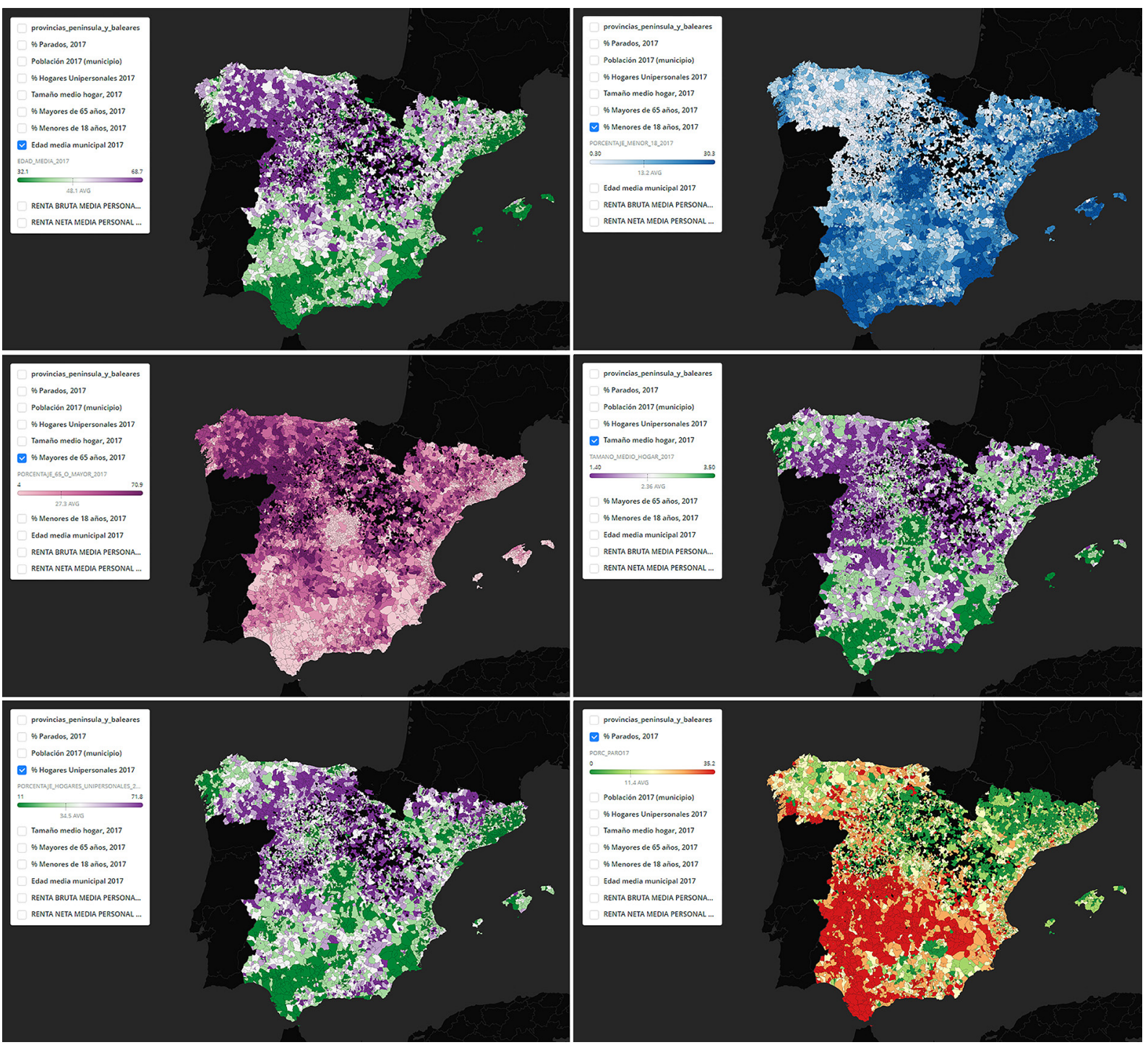

Fuente: AEAT, INE. Elaboración propia. Imágenes extraídas de la aplicación web desarrollada

\subsection{Caracterización de clústeres}

Como parte del análisis exploratorio de los datos espaciales se ha elaborado también una identificación y clasificación de conglomerados (clústeres), utilizando las fuentes de ingreso de las rentas brutas medias (en porcentaje y en euros), además de un análisis de clúster y outlier a partir de la renta neta media por persona, siempre para el año 2017. La intención de estos análisis es presentar una primera aproximación para su incorporación a la aplicación web y mejorar el análisis de los datos a través de su geovisualización espacial y las interacciones con otras variables que se facilitan a través de los widgets (ver $\underline{\text { Cliente 3). }}$.

\subsubsection{Clasificación de conglomerados (clústeres) a partir de las fuentes de ingreso expresadas en porcentajes}

Como se ha comentado en secciones anteriores, una de las singularidades de esta nueva fuente de datos es el hecho de que presente la distribución de las fuentes de ingreso, expresada en las primeras ediciones del ADRH como porcentajes de las rentas brutas medias para cada municipio (INE, 2019). Por ello, se ha realizado un primer análisis de conglomerados utilizando las cinco fuentes de ingreso expresadas en porcentajes para el ámbito geográfico definido. Como se explicó en la sección de metodología, con 
objeto de obtener un primer conjunto de conglomerados 'naturales' se utiliza el análisis de asignación de conglomerados de ArcGIS 10.8 mediante la herramienta de análisis estadístico espacial grouping. Como puede observarse en la Figura 7, extraída del Cliente 3, tras activar el parámetro 'evaluar número óptimo de grupos' en este software y analizar el informe generado, se opta por la opción de cuatro clases, al estar asociada con uno de los mayores valores del estadístico pseudo F. Los valores más altos en el mismo indican las soluciones más eficaces para garantizar las mayores similitudes dentro de cada grupo y las mayores diferencias entre grupos. En la Figura 7 también puede observarse la distribución geográfica de estas cuatro clases o grupos y el diagrama de caja paralelo con los valores de las variables estandarizadas para cada uno de ellos (con correspondencia de colores).

Figura 7. Clústeres según fuentes de ingresos (\%), 2017
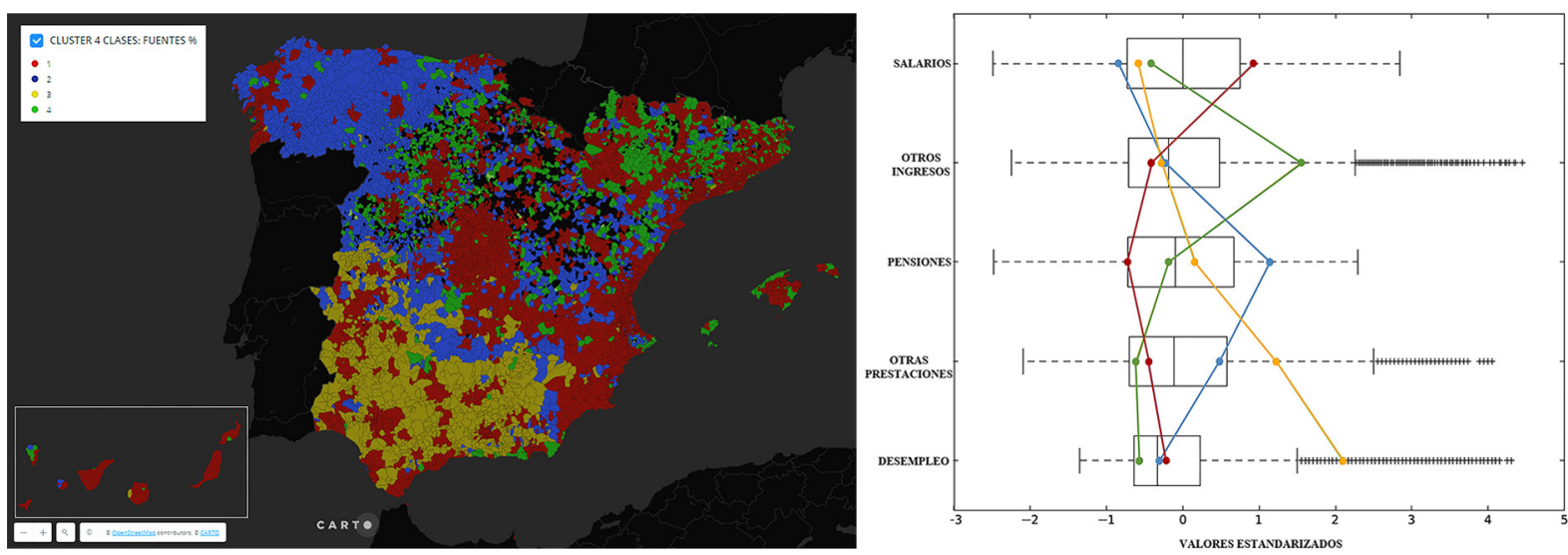

Fuente: AEAT, INE. Elaboración propia. Imagen extraída de la aplicación web desarrollada y box plot resultante del análisis en ArcGIS 10.8

Las cuatro clases o grupos generados presentan un patrón espacial claro, que puede definirse como sigue:

a. Clase 1 (en rojo): se identifica con los municipios con población urbana (eje mediterráneo, corredor Madrid-Valencia, etc.), las principales conurbaciones asociadas a las capitales, grandes ciudades y municipios más dinámicos. Como puede verse en el diagrama (línea roja), este clúster se caracteriza por presentar el porcentaje estandarizado más alto en los ingresos provenientes de los salarios; el porcentaje más bajo en relación con las pensiones; porcentajes por debajo de la mediana en cuanto a otros ingresos y otras prestaciones; y un porcentaje algo superior a la mediana en relación con los ingresos por desempleo.

b. Clase 2 (en azul): desde un punto de vista geográfico, se identifica genéricamente con el cuadrante noroeste peninsular, municipios rurales asociados a áreas de montaña (Sistema Ibérico) y aquellos con un índice de envejecimiento elevado. Se caracteriza por presentar el porcentaje estandarizado más alto de ingresos derivados de las pensiones; porcentajes altos para los derivados de otras prestaciones; un porcentaje coincidente con la mediana en cuanto a los ingresos provenientes de otros ingresos y de desempleo; y, el menor porcentaje en relación con los ingresos derivados de los salarios (línea azul en el diagrama).

c. Clase 3 (en amarillo): se identifica con las comunidades autónomas de Andalucía, Extremadura y áreas limítrofes, con la excepción de sus áreas urbanas y municipios medios más dinámicos (clase 1). Se caracteriza por presentar los porcentajes estandarizados más elevados en los ingresos procedentes del desempleo (los más alejados de la mediana de todas las fuentes y clases) y de otras prestaciones; un porcentaje por encima de la mediana en cuanto a pensiones; un porcentaje en la mediana en cuanto a otros ingresos; y un porcentaje bajo en cuanto a ingresos derivados de salarios (línea amarilla del diagrama).

d. Clase 4 (en verde): se trata de la clase más dispersa geográficamente, aunque se concentra en su mayor parte en el norte de las comunidades autónomas de Cataluña, Aragón y sector oriental de Castilla y León. Se caracteriza por presentar los porcentajes estandarizados más altos de otros ingresos; porcentajes por debajo de la mediana en cuanto a salarios y pensiones; y los valores más bajos en los porcentajes de ingresos derivados de otras prestaciones y de desempleo (línea verde del diagrama). 


\subsubsection{Clasificación de conglomerados (clústeres) a partir de las fuentes de ingreso expresadas en euros}

De acuerdo a la actualización metodológica realizada por el INE para la elaboración del ADRH en diciembre de 2020, se ha realizado una segunda clasificación de clústeres a partir de las cinco fuentes de ingreso de la renta bruta media personal, en esta ocasión, expresadas en euros (INE, 2020a). En esta clasificación se pueden apreciar diferencias importantes respecto a la derivada de los datos expresados en porcentaje (INE, 2019), ya que los valores de un mismo porcentaje se incrementarán en función del valor de la renta bruta media por persona (con una clara tendencia espacial positiva 'sur-norte') ${ }^{30}$. Aunque el patrón espacial puede parecer similar, del análisis que se representa en la Figura 8 se derivan resultados novedosos y diferencias significativas.

Figura 8. Clústeres según fuentes de ingresos (€), 2017
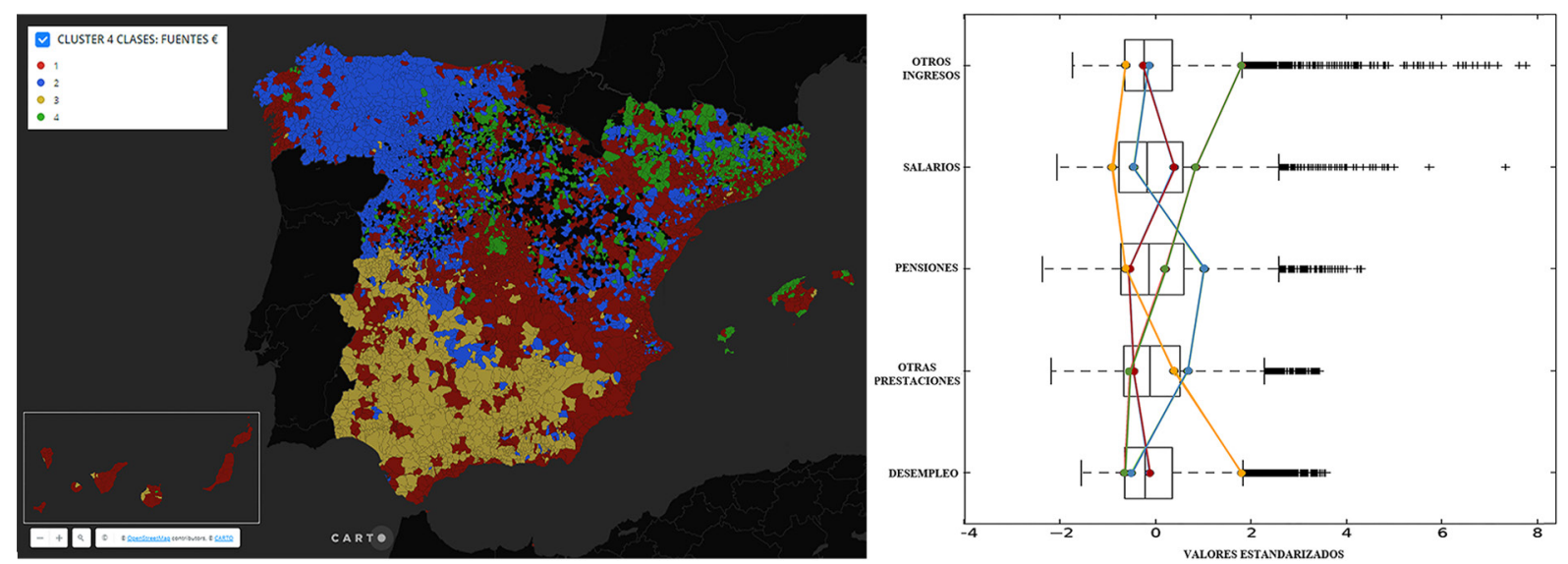

Fuente: AEAT, INE. Elaboración propia. Imagen extraída de la aplicación web desarrollada y box plot resultante del análisis en ArcGIS 10.8

a. Clase 1 (en rojo): desde el punto de vista de su distribución espacial, el patrón espacial es similar al expuesto en la clasificación anterior. Sin embargo, hay que llamar la atención sobre el hecho de que las ciudades de Madrid y Barcelona no quedan incluidas en esta clase. Como puede verse en el diagrama (línea roja) esta clase sigue presentando un valor alto en cuanto a ingresos estandarizados por salarios, aunque se matiza; presenta valores coincidentes con la mediana en relación con otros ingresos y desempleo; y valores bajos relativos a ingresos por otras prestaciones y pensiones.

b. Clase 2 (en azul): se identifica con una distribución espacial casi idéntica al análisis anterior, pero en este caso se matiza el protagonismo de las pensiones, que sigue presentando los mayores valores estandarizados, así como para ingresos por otras prestaciones; los valores relativos a otros ingresos aumentan significativamente situándose en la mediana; aumentan los valores derivados de los salarios, aunque en este caso se mantienen por debajo de la mediana; y se observa un valor estandarizado más bajo en cuanto a ingresos por desempleo.

c. Clase 3 (en amarillo): de nuevo, la distribución espacial es muy similar a la anterior, aunque en este caso presenta los valores estandarizados más bajos en cuanto a ingresos procedentes de los salarios, otros ingresos y pensiones, que representan la mayor proporción de la renta (Tabla 1); valores por encima de la mediana en relación con otras prestaciones; y los valores más altos por desempleo, que paradójicamente, además, son los que presentan una menor proporción de la renta.

d. Clase 4 (en verde): en relación con su distribución espacial, la diferencia más importante que deriva de este segundo análisis es la incorporación de Madrid y Barcelona. Ahora presenta los valores estandarizados más altos en relación con otros ingresos y salarios, aumenta los valores correspondientes a pensiones y presenta los valores más bajos en cuanto a otras prestaciones y desempleo.

30 Se puede revisar esta variable en el Cliente 3. 


\subsubsection{Análisis de clúster y de valor atípico (I Anselin local de Moran)}

En este tipo de análisis, dado un conjunto de entidades (en este caso, municipios) y un campo de análisis (renta neta media por persona de 2017), la herramienta 'análisis de clúster y de valor atípico' identifica clústeres espaciales de las entidades con valores altos o bajos, así como valores atípicos (outliers). Para realizar este análisis, la herramienta calcula un valor I de Moran local, una puntuación z, un pseudo valor $\mathrm{P}$ y un código que representa el tipo de clúster para cada entidad estadísticamente significativa. Las puntuaciones z y los pseudo valores P representan la significación estadística de los valores del índice calculado. Los resultados distinguen entre un clúster estadísticamente significativo de valores altos (AA), un clúster de valores bajos (BB), valores atípicos en el que un valor alto está rodeado principalmente por valores bajos $(\mathrm{AB})$ y otros valores atípicos en el que un valor bajo está rodeado principalmente por valores altos (BA). La significación estadística está establecida en un nivel de confianza del $95 \%$.

La Figura 9 recoge los resultados de estos análisis realizados con dos herramientas: la correspondiente en ArcGIS 10.8 (Figura 9a) y la realizada dentro de la propia plataforma cloud de CARTO (Figura 9b), al ser este uno de los análisis que se ofrecen a todos los usuarios. Este tipo de análisis permite al usuario conceptualizar y modelar relaciones espaciales entre entidades geométricas — siendo ésta la principal diferencia con los análisis de conglomerados antes presentados, en los que no se impuso ni modeló ninguna relación espacial-, con diferentes parámetros (distancia fija umbral para seleccionar vecinos, números de vecinos, etc.). Como en el caso de las figuras anteriores, los ejemplos representados en la Figura 9 solo tienen la intención de mostrar algunas de las posibilidades existentes para mejorar el análisis exploratorio preliminar de los datos, una vez que ambas clasificaciones han sido incorporadas a la aplicación web de consulta creada.

Figura 9. Clúster y valor atípico a partir de renta neta media por persona, 2017: (a) calculado para una distancia de $150 \mathrm{~km}$ (ArcGIS 10.8) y (b) calculado para los cinco vecinos más cercanos (CARTO)

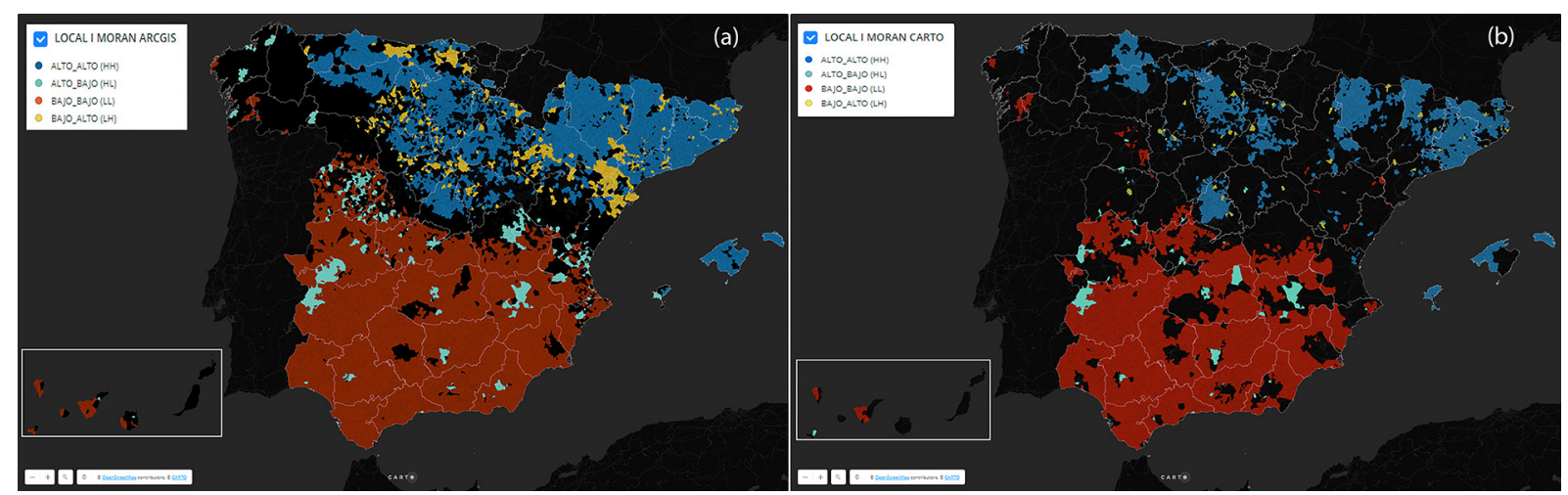

Fuente: AEAT, INE. Elaboración propia. Imágenes extraídas de la aplicación web desarrollada

En el caso del análisis realizado con ArcGIS, el parámetro para la selección de vecinos fue la distancia umbral de $150 \mathrm{~km}$. (calculada sobre el sistema de coordenadas proyectadas ETRS89_UTM30 N) y el método de conceptualización inverse_distance, mientras para el análisis realizado en la plataforma cloud de CARTO se utilizaron cinco vecinos. De estos análisis, y con ambas herramientas, se desprende una clara dicotomía sur-norte: los clústeres significativos de valores altos-altos y bajos-bajos presentan una nítida concentración territorial (en el norte y en el sur, respectivamente), identificándose solo algunas unidades territoriales con un comportamiento distinto al de las unidades vecinas (outliers). De esta forma, la mitad sur peninsular concentra un clúster con un predominio claro de valores bajos-bajos (BB) en ambos análisis, mientras los valores altos-altos (AA) se concentran en el sector norte peninsular y Baleares (con la excepción del noroeste peninsular), si bien presentan un patrón más extenso y continuo espacialmente en el análisis realizado con ArcGIS (distancia umbral de $150 \mathrm{~km}$ ) y más reducido, disperso y desconectado en el análisis realizado en la plataforma de CARTO (cinco vecinos).

\section{Discusión de resultados}

La oportunidad que ofrecen los nuevos datos del ADRH — parte nuclear de este trabajo- contrasta con el escaso uso que han tenido por parte de la comunidad geográfica española. Son escasos los trabajos 
que mencionan o utilizan esta fuente de datos (Checa, Martín, López \& Nel·lo, 2020; González \& Piñeira, 2020) y no se ha localizado ninguna publicación científica que presente y haga uso de todo el potencial del citado Atlas. Precisamente, la principal novedad y el carácter original del trabajo que aquí se presenta está relacionado con el hecho de que se logran superar las limitaciones que hasta el momento han presentado las fuentes de datos tradicionales para el análisis de la distribución de la renta de los hogares de España. Entre estas fuentes, la Encuesta de Presupuestos Familiares y la Encuesta de Condiciones de Vida han permitido desarrollar investigaciones de gran interés, pero limitadas por su carácter muestral. Por su parte, la Estadística de los Declarantes del IRPF y la Estadística de los Declarantes del IRPF de los Mayores Municipios por Código Postal presentan una mayor desagregación (provincial, municipal e inframunicipal, respectivamente) pero también cuenta con la limitación de que solo se ofrecen datos para municipios que superen un determinado umbral de población, de declaraciones o de renta bruta agregada, según el caso, además de que no incluye a aquellos que se sitúan por debajo del umbral de declaración (no declarantes). Por tanto, los trabajos realizados a partir de estas fuentes - que en todos los casos confirman la reducción de la renta media y el incremento de la desigualdad en España (Anghel et al., 2018; Ayala, 2016; Ayala \& Cantó, 2020; Ayala \& Ruiz-Huerta, 2020; Hortas \& Onrubia, 2014, 2020; Hortas \& Ríos, 2019) — no han podido incorporar el análisis del nivel de detalle territorial que se ofrece en esta investigación.

Además, este trabajo incluye una solución original, novedosa y de gran interés para la Geografía, basada en una aplicación web desarrollada en un entorno cloud (geovisores, widgets y dashboards), pública y reutilizable, que amplía las posibilidades de análisis de los geovisores web ofrecidos por el INE y la AEAT en cuanto a su nivel de interacción, posibilidades de exploración y filtrado en tiempo real. Esta aplicación web -que se concreta en cinco clientes a través de los que se transfiere en abierto el resultado de la investigación - no solo permite la geovisualización de la información y el desarrollo de herramientas interactivas (widgets) sino que, además, y aún más importante, facilita una nueva forma de interaccionar con los datos enfatizando el análisis exploratorio de datos espaciales (Sánchez, Martín \& Rengifo, 2019). Este Análisis Exploratorio de Datos Espaciales (AEDE), paradójicamente, ha estado más extendido en el campo de la econometría espacial como trabajo previo al análisis confirmatorio o a la modelización y a la propia definición de hipótesis, que no se formulan hasta identificar estructuras espaciales en las variables estudiadas (Anselin, 1999; Chasco, 2003; Moreno \& Vayá, 2002).

Entre las opciones de exploración preliminar se sitúan los análisis de conglomerados realizados con los datos de las fuentes de ingreso de las rentas brutas expresadas en porcentaje (INE, 2019) y en euros (INE, 2020a), así como los análisis de clúster y valor atípico a partir de la renta media por persona, que se presentan, por primera vez, a la escala municipal más detallada. Aunque se trata de análisis preliminares, sus resultados coinciden con los de trabajos previos en cuanto a la existencia de una fuerte desigualdad sur-norte (Buendía \& Sánchez, 2013; Delgado, 2006; Guisán, 2017; INE, 2020b; López-Bazo, del Barrio $\&$ Artis, 2002; Manzanares \& Riquelme, 2017). Aunque, como se ha señalado, estas clasificaciones no tienen la pretensión de dar respuestas definitivas, sí llaman la atención sobre cuestiones escasamente conocidas, como el patrón espacial que confirman las clases definidas o, por ejemplo, la importancia de la fuente de ingresos provenientes de las pensiones que puede llegar a superar a los provenientes de los salarios en numerosos municipios (en azul en la Figura 10b). Con ello, se ejemplifica la potencialidad de estas nuevas herramientas en entornos cloud, que se enmarcan en el cuarto paradigma científico (Ojeda \& Paneque, 2019), así como su enorme potencial para el análisis geográfico, ya que la propia estructura dual de los datos geográficos (geometría y variables temáticas) incrementa las necesidades de computación y estos entornos facilitan su escalabilidad vertical u horizontal de forma muy eficiente y cómoda para el usuario.

Por otra parte, el cálculo de algunas variables agregadas de las fuentes de ingreso y su geovisualización permiten cuestionar creencias basadas en una suerte de 'mitología territorial' que ha situado y estigmatizado al sur peninsular como una región fuertemente subvencionada, sin serlo. Como se observa en la Figura 10a, y a modo de ejemplo de lo que puede analizarse con más detalle en el Cliente 3, el simple sumatorio de todas las fuentes de ingresos no procedentes del mercado, es decir, las prestaciones de pensiones, otras prestaciones y el desempleo, refleja un patrón espacial dondeel área más 'beneficiada' no resulta ser precisamente el sur peninsular. 
Figura 10. Variables calculadas, 2017. (a) Sumatorio del total de prestaciones (pensiones, otras prestaciones y desempleo) en euros. (b) Resta de salarios menos prestaciones en euros

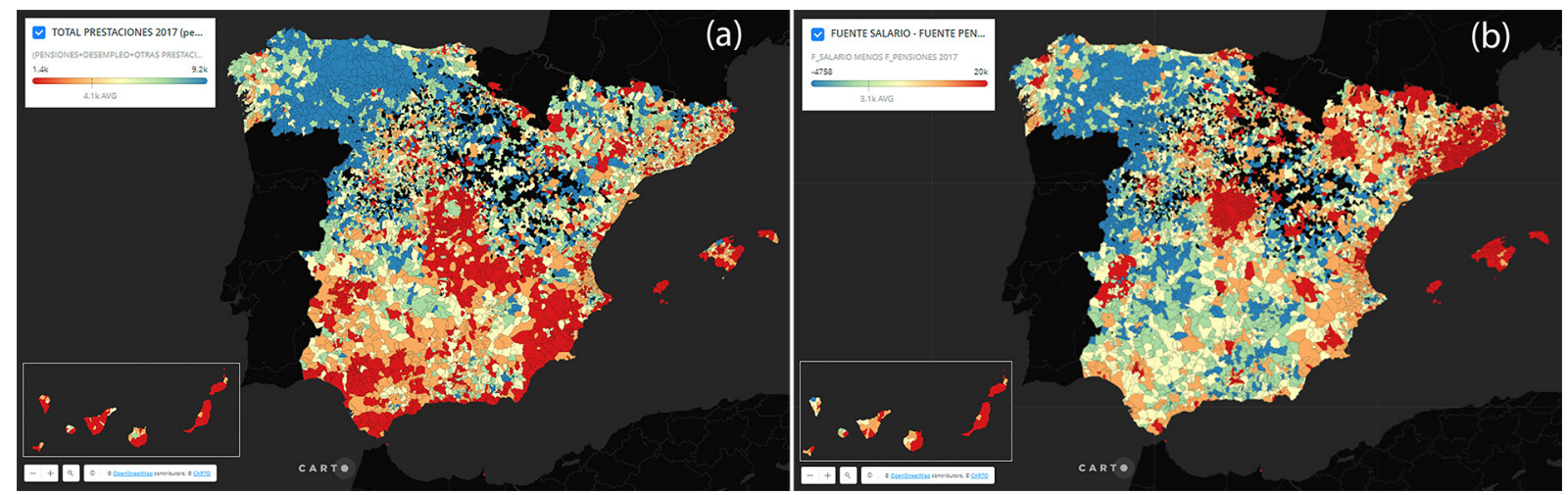

Fuente: AEAT, INE. Elaboración propia. Imágenes extraídas de la aplicación web desarrollada

Si algo puede y debe aportar la Geografía, en un momento caracterizado por la desinformación y la polarización, son nuevos análisis espaciales de detalle, basados en datos oficiales y rigurosos, que permitan avanzar hacia posiciones de mayor solidaridad territorial y hacia estrategias y políticas compensatorias, que eviten la consecuencias de lo que Rodríguez-Pose bien denominó como 'la venganza de los lugares que no importan' (2018), que es susceptible de materializarse en votos desafectos y en una ruptura social y regional cada vez más amplia. El debate sobre la potenciación de mecanismos como el Fondo de Compensación Interterritorial (Fernández \& Murillo, 2020) o el Ingreso Mínimo Vital (Doménech, 2017; Noguera, 2019) pueden y deben ser alimentados por nuevos análisis espaciales, como los que podrían derivarse del uso de datos y tecnologías utilizados en este trabajo.

\section{Conclusiones}

El estudio de la desigualdad ocupa un lugar esencial en el marco de las Ciencias Sociales (Díez, Martínez \& Tirado, 2018; Piketty \& Sáez, 2003; Novotny, 2007; Wei, 2015; Tirado, Díez \& Martínez, 2016). El análisis de las relaciones entre los procesos territoriales, el desarrollo económico y el bienestar de la ciudadanía ha sido estudiado tradicionalmente por la geografía económica y la geografía social (Fujita \& Krugman, 2005; Garretsen \& Martin, 2010; Smith \& Reid, 2017) y ha tenido una plasmación práctica en políticas de desarrollo regional, tanto en el contexto europeo como en el nacional que, aun teniendo un efecto positivo, en casos como el de España, no han logrado consolidar una situación de convergencia (Fernández \& Murillo, 2020). Estas políticas han movilizado importantes recursos con el objetivo último de aumentar la equidad territorial, pero puede afirmarse que la brecha regional, también en España, se ha acrecentado en las últimas décadas y aún más tras la crisis financiera de 2008 y se prevé difícil de reducir en un nuevo contexto de crisis, en este caso definido por las consecuencias sociales y económicas de la COVID-19 (Ayala \& Ruiz-Huerta, 2020).

Los procesos de urbanización y envejecimiento de la población —imparables e inacabados en el momento actual - hacen urgente avanzar en estudios más detallados sobre la distribución de la renta por fuentes de ingreso a escala nacional, regional y local. Esta cuestión resulta clave al haberse constatado que los factores que mejor explican la desigualdad en España son aquellos relacionados con el aumento del desempleo, su descendente tasa de cobertura, la precarización laboral o el descenso de los salarios mínimos (Ayala \& Cantó, 2020; CES, 2013; Davia, 2014; FOESSA, 2015; Goerlich, 2016, 2017; Larraz, et al., 2020). Análisis más detallados sobre estas cuestiones resultan esenciales para lograr una comprensión mayor y más completa de las causas que generan y perpetúan situaciones de desigualdad, además del alcance y la naturaleza de dicha realidad.

Las novedades relativas a la fuente de datos, a la escala y a la metodología de trabajo, así como los resultados obtenidos en esta investigación, quieren ser el comienzo de una nueva línea de trabajo centrada en la exploración y el análisis de indicadores de desigualdad, sus patrones espaciales y los desequilibrios territoriales en España. La aparición de las estadísticas experimentales del INE abre nuevas posibilidades para la ciencia geográfica y permite la construcción de nuevas hipótesis de trabajo. 
En este trabajo, se han podido contrastar y confirmar las hipótesis iniciales y, además, han aparecido otras nuevas, que darán continuidad a esta línea de investigación, relativas al mayor grado de desigualdad intracomunitaria e intramunicipal (Ayala, Jurado \& Pérez, 2020) o a la exploración de los datos a nivel de sección censal y de nuevos indicadores, como los recientemente publicados índices de Gini (INE, 2020a).

\section{Financiación}

Plataforma Cloud para la Integración Espacial de Geoinformación ambiental y socioeconómica (Spatial Big Data) y Clientes Web Interactivos (Geovisores, DashBoard) para su difusión, acceso, explotación y análisis (Maching Learning). Proyecto singular de actuaciones de transferencia CEI RIS3. Junta de Andalucía. Andalucía Tech CEI-9.

Prototipo Cloud de Evaluación de Riesgos a Través de la Integración Espacial de Geodatos (Grid Multiescalares) y Clientes Web (Dashboard) para su Gestión y Medidas de Adaptación. Proyecto Plan Estatal I+D+i Retos. Ministerio de Ciencia e Innovación. PID2019-106834RB-I00.

E-Infraestructura (Cloud Computing) para la Integración Espacial de Variables Antrópicas en el Cálculo de la Vulnerabilidad ante Riesgos Costeros y Herramientas Web (Dashboard) para su Gestión en Andalucía (Clodrisk_A). Proyecto I+D+i Frontera. Junta de Andalucía. P18-FR-2574.

\section{Referencias}

Anghel, B., Basso, H. S., Bover Hidiroglu, O., Casado García, J. M., Hospido Quintana, L., Kataryniuk, I. ... \& Vozmediano Peraita, E. (2018). La desigualdad de la renta, el consumo y la riqueza en España. Madrid: Banco de España. Documentos Ocasionales, ${ }^{\circ} 1.806$. Recuperado de https://repositorio.bde. es/handle/123456789/8774

Anselin, L. (1999). The future of spatial analysis in the social sciences. Geographic Information Sciences, 5(2), 67-76. https://doi.org/10.1080/10824009909480516

Ash, J., Kitchin, R., \& Leszczynski, A. (2016). Digital turn, digital geographies? Progress in Human Geography, 42(1), 25-43. https://doi.org/10.1177/0309132516664800

Ayala Cañón, L. (2016). La desigualdad en la distribución personal de la renta en España. Revista de Libros. Recuperado de https://www.revistadelibros.com/discusion/la-desigualdad-en-la-distribucionpersonal-de-la-renta-en-espana

Ayala Cañón, L., \& Cantó Sánchez, O. (2020). Mercado de trabajo y desigualdad. En A. Blanco et al., Informe España 2020 (pp. 173-220). Madrid: Universidad Pontificia Comillas, Cátedra J.M. Martín Patino.

Ayala Cañón, L., \& Ruiz-Huerta Carbonell, J. (Dir.) (2020). $4^{\circ}$ Informe sobre la Desigualdad en España. Una perspectiva territorial. Madrid: Fundación Alternativas. Recuperado de https://www. fundacionalternativas.org/laboratorio/libros-e-informes/informes/4o-informe-sobre-la-desigualdaden-espana-una-perspectiva-territorial

Ayala, L., Jurado, A., \& Pérez Mayo, J. (2020). Diferencias de desigualdad y bienestar en las regiones españolas. In L. Ayala Cañón \& J. Ruiz-Huerta Carbonell (Dir.), $4^{\circ}$ Informe sobre la Desigualdad en España. Una perspectiva territorial (pp. 121-150). Madrid: Fundación Alternativas.

Ayala, L., Martín Román, J., \& Vicente Perdiz, J. (2020). The Contribution of the Spatial Dimension to Inequality: A Counterfactual Analysis for OECD Countries. Papers in Regional Science, 99(3), 447-477. https://doi.org/10.1111/pirs.12503

Brynjolfsson, E., \& Mcafee, A. (2014). The Second Machine Age: Work, Progress, and Prosperity in a Time of Brilliant Technologies. New York: Norton \& Company.

Buendía, J. D., \& Sánchez, M. M. (2013). La distribución del desempleo en las provincias españolas. Un análisis con datos de panel mediante el filtrado espacial. Investigaciones Regionales, 27, 143-154. Recuperado de https://old.aecr.org/images/ImatgesArticles/2013/11/06_Buendia.pdf? $\mathrm{ga}=2.130121612 .2033882605 .1611075925-43197235.1611075925$ 
Castells-Quintana, D., Ramos, R., \& Royuela, V. (2015). Income inequality in European Regions. Recent trends and determinants. Review of Regional Research, 35, 123-146. https://doi.org/10.1007/s10037015-0098-4

CES, Consejo Económico y Social (2013). Distribución de la renta en España: desigualdad, cambios estructurales y ciclos. Informe 03/2013. Recuperado de https://www.siis.net/es/documentacion/verseleccion-novedad/197801/

Chasco Yrigoyen, C. (2003). Econometría espacial aplicada a la predicción-extrapolación de datos microterritoriales. Madrid: Consejería de Economía e Innovación Tecnológica.

Checa, J., Martín, J., López, J., \& Nel-lo, O. (2020). Those who cannot stay at home: urban mobility and social vulnerability in Barcelona during the COVID-19 pandemic. Boletín de la Asociación de Geógrafos Españoles, (87). https://doi.org/10.21138/bage.2999

Davia, M. A. (2014). Evolución del empleo de bajos salarios en España. En VII Informe sobre exclusión y desarrollo social en España 2014 (Documento de Trabajo 4.2.). Madrid: Fundación FOESSA.

Delgado Cabeza, M. (2006). Economía, territorio y desigualdades regionales. Revista de estudios regionales, 75, 93-128. Recuperado de http://www.revistaestudiosregionales.com/documentos/articulos/pdf835. pdf

Díez Minguela, A., Martínez Galarraga, J., \& Tirado Fabregat, D.A. (2018). Regional Inequality in Spain 1860-2015. Palgrave Macmillan. https://doi.org/10.1007/978-3-319-96110-1

Doménech, R. (2017, April 20). Algunas reflexiones sobre la Renta Básica Universal. In BBVA Research. Recuperado de https://www.bbvaresearch.co/ublicacione/lgunas-reflexiones-sobre-la-renta-basicauniversal/

EU, European Union (2019). Regional inequalities in the EU (Briefing). European Parliamentary Research Service (PE 637.951). Recuperado de https://www.europarl.europa.eu/RegData/etudes/ BRIE/2019/637951/EPRS_BRI(2019)637951_EN.pdf

Fernández Llera, R., \& Murillo, E. (2020). Las políticas de desarrollo regional en España. En L. Ayala Cañón \& J. Ruiz-Huerta Carbonell (Dirs.), $4^{\circ}$ Informe sobre la Desigualdad en España. Una perspectiva territorial (pp. 121-150). Madrid: Fundación Alternativas.

FOESSA (2015). Empleo precario y protección social. Análisis y Perspectivas 2015. Madrid: Fundación FOESSA. Recuperado de https://korimaclaretianas.files.wordpress.com/2015/11/analisis-yperspectivas-2015.pdf

Fujita, M., \& Krugman, P. (2005). The new economic geography: Past, present and the future. Papers in Regional Science, 83, 139-164. https://doi.org/10.1007/s10110-003-0180-0

Garretsen, H., \& Martin, R. (2010). Rethinking (New) Economic Geography Models: Taking Geography and History More Seriously. Spatial Economic Analysis, 5, 127-160. https://doi. org/10.1080/17421771003730729

Goerlich, F. J. (2016). Distribución de la renta, crisis económica y políticas redistributivas. Bilbao: Fundación BBVA. Recuperado de https://www.fbbva.es/publicaciones/distribucion-de-la-renta-crisis-economicay-politicas-redistributivas/

Goerlich, F. J. (2017). Distribución de la renta en España: 2004-2013. Semestre Económico 20(42), 47-72. https://doi.org/10.22395/seec.v20n42a2

González Pérez, J. M., \& Piñeira Mantiñán, M. J. (2020). The unequal city in Palma (Majorca): Geography of confinement during the COVID-19 pandemic. Boletín de la Asociación de Geógrafos Españoles, (87). https://doi.org/10.21138/bage.2998

Graham, M., \& Shelton, T. (2013). Geography and the future of big data, big data and the future of geography. Dialogues in Human Geography, 3(3), 255-261. https://doi.org/10.1177/2043820613513121

Gray, J., \& Szalay, A. (2007). eScience - A Transformed Scientific Method (Presentation to the Computer Science and Technology Board of the National Research Council, Mountain View, CA). Recuperado de http://research.microsoft.com/en-us/um/people/gray/talks/NRC-CSTB_eScience.ppt

Guisán, M. C. (2017). Desenvolvemento económico rexional de España, 1986-2013: 25 anos de evolución. Revista Galega de Economía, 26(2). Recuperado de https://revistas.usc.gal/index.php/rge/ article/view/4448 
Gutiérrez-Puebla, J. (2018). Big Data y nuevas geografías: la huella digital de las actividades humanas. Documents d'Anàlisi Geogràfica 2018, 64/2, 195-217. https://doi.org/10.5565/rev/dag.526

Gutiérrez-Puebla, J., García-Palomares, J. C., \& Salas-Olmedo, M. H. (2016). Big (Geo)Data en Ciencias Sociales: Retos y Oportunidades. Revista De Estudios Andaluces, 33, 1-23. https://doi.org/10.12795/ rea.2016.i33.01

Hey, T., Tansley, S., \& Tolle, Y. K. (Eds.) (2014). El cuarto paradigma. Descubrimiento científico intensivo en datos. México: Microsoft Research \& Universidad Autónoma Metropolitana.

Hortas Rico, M., \& Onrubia, J. (2014). Renta personal de los municipios españoles y su distribución: Metodología de estimación a partir de microdatos tributarios (Estudios Sobre la economía española - 2014/12). FEDEA.

Hortas Rico, M., \& Onrubia, J. (2020). Renta personal de los municipios españoles y su distribución, años 2011 y 2014 (Apuntes - 2020/1). FEDEA

Hortas Rico, M., \& Ríos, V. (2019). The drivers of local income inequality: A spatial Bayesian modelaveraging approach. Regional Studies, 53(8), 1207-1220. https://doi.org/10.1080/00343404.2019.15 $\underline{66698}$

INE, Instituto Nacional de Estadística (2019). Atlas de distribución de renta de los hogares (ADRH) (Proyecto técnico). Subdirección General de Estadísticas Sociodemográficas.

INE, Instituto Nacional De Estadística (2020a). Atlas de distribución de renta de los hogares (ADRH). Proyecto técnico. Subdirección General de Estadísticas Sociodemográficas. Recuperado de https:// www.ine.es/experimental/atlas/exp_atlas_proyecto.pdf

INE, Instituto Nacional De Estadística (2020b). Contabilidad Regional de España. Revisión Estadística 2019. Recuperado de https://www.ine.es/prensa/cre 2019_2.pdf

Johnston, R., Harris, R., Jones, K., Manley, D., Sabel, C. E., \& Wang, W. W. (2014). One step forward but two steps back to the proper appreciation of spatial science. Dialogues in Human Geography, 4(1), 59-69. https://doi.org/10.1177/2043820614526818

Kitchin, R. (2013). Big data and human geography: Opportunities, challenges and risks. Dialogues in Human Geography, 3(3), 262-267. https://doi.org/10.1177/2043820613513388

Larraz, B., Pavía, J. M., \& Herrera Gómez, M. (2020). Spatial aggregation and resampling expansion of big surveys: An analysis of wage inequality. Regional Science Policy and Practice. https://doi.org/10.1111/ rsp3.12333

López-Bazo, E., del Barrio, T., \& Artis, M. (2002). The regional distribution of Spanish unemployment. A spatial analysis. Papers in Regional Sciencie, 81(3), 365-389. https://doi.org/10.1111/j.1435-5597.2002. tb01239.x

Manzanares Gutiérrez, A., \& Riquelme Perea, P. J. (2017). Análise espacial do desemprego nos mercados locais de traballo españois. Revista Galega de Economía, 26(2). Recuperado de https://revistas.usc.gal/ index.php/rge/article/view/4469

Moreno Serrano, R., \& Vayá Valcarce, E. (2002). Econometría espacial: nuevas técnicas para el análisis regional. Una aplicación a las regiones europeas. Investigaciones Regionales, (1), 83-106.

Noguera, J. A. (2019). The Political Debate on Basic Income and Welfare Reform in Spain. Social Policy and Society, 18(2). https://doi.org/10.1017/S1474746418000271

Novotny, J. (2007). On the measurement of regional inequality: does spatial dimension of income inequality matter? Annals of Regional Science, 41(3), 563-580. https://doi.org/10.1007/s00168-0070113-y

OECD (2015). In it together: Why less inequality benefits all. Paris: OECD Publishing. https://doi. org/10.1787/9789264235120-en

OECD (2020) Income inequality (OECD data). Recuperado de https://data.oecd.org/inequality/incomeinequality.htm

Ojeda Zújar, J., \& Paneque, P. (2019). Big data y Geografía. En Colección Geografía 2020 - Generando discurso. Madrid: Asociación Española de Geografía. Recuperado de https://www.age-geografia.es/ site/wp-content/uploads/2019/12/generando-discurso-1-1.pdf 
Piketty, T., \& Sáez, E. (2003). Income Inequility in the United States, 1913-1998. Quarterly Journal of Economics, 118(1), 1-41. https://doi.org/10.1162/00335530360535135

Rodríguez-Pose, A. (2018). The revenge of places that don't matter (and what to do about it). Cambridge Journal of Regions, Economy and Society, 11(1). https://doi.org/10.1093/cjres/rsx024

Sánchez Martín, J. M., Martín Delgado, L. M., \& Rengifo Gallego, J. I. (2019). La reputación online de los alojamientos rurales en Extremadura desde una óptica geoestadística. Boletín De La Asociación De Geógrafos Españoles, (82). https://doi.org/10.21138/bage.2758

Schwab, K. (2017). La cuarta revolución industrial. Madrid: Debate.

Smith, T., \& Reid, L. (2017). Which 'being' in wellbeing? Ontology, wellness and the geographies of happiness. Progress in Human Geography, 42(6). https://doi.org/10.1177/0309132517717100

Tirado, D. A., Díez Minguela, A., \& Martínez Galarraga, A. (2016). Regional inequality and economic development in Spain, 1860-2010. Journal of Historical Geography, 54, 87-98. https://doi.org/10.1016/j. jhg.2016.09.005

Wei, Y. D. (2015). Spatiality of regional inequality. Applied Geography, 61. https://doi.org/10.1016/j. apgeog.2015.03.013 